\title{
Benchmarking Density Functional Approximations for Excited-State Properties of Fluorescent Dyes
}

\author{
Anna M. Grabarz ${ }^{1, *(D)}$ and Borys Ośmiałowski ${ }^{2}$ D \\ 1 Faculty of Chemistry, Wrocław University of Science and Technology, Wyb. Wyspiańskiego 27, \\ PL-50370 Wrocław, Poland \\ 2 Faculty of Chemistry, Nicolaus Copernicus University, Gagarina 7, PL-87100 Toruń, Poland; \\ borys.osmialowski@umk.pl \\ * Correspondence: anna.grabarz@pwr.edu.pl
}

Citation: Grabarz, A.M;

Ośmiałowski, B. Benchmarking Density Functional Approximations for Excited-State Properties of Fluorescent Dyes. Molecules 2021, 26, 7434. https://doi.org/10.3390/ molecules26247434

Academic Editor: Barbara Panunzi

Received: 25 October 2021

Accepted: 4 December 2021

Published: 8 December 2021

Publisher's Note: MDPI stays neutral with regard to jurisdictional claims in published maps and institutional affiliations.

Copyright: (C) 2021 by the authors. Licensee MDPI, Basel, Switzerland. This article is an open access article distributed under the terms and conditions of the Creative Commons Attribution (CC BY) license (https:/ / creativecommons.org/licenses/by/ $4.0 /)$
Abstract: This study presents an extensive analysis of the predictive power of time-dependent density functional theory in determining the excited-state properties of two groups of important fluorescent dyes, difluoroboranes and hydroxyphenylimidazo[1,2-a]pyridine derivatives. To ensure statistically meaningful results, the data set is comprised of 85 molecules manifesting diverse photophysical properties. The vertical excitation energies and dipole moments (in the electronic ground and excited states) of the aforementioned dyes were determined using the RI-CC2 method (reference) and with 18 density functional approximations (DFA). The set encompasses DFAs with varying amounts of exact exchange energy (EEX): from $0 \%$ (e.g., SVWN, BLYP), through a medium (e.g., TPSSh, B3LYP), up to a major contribution of EEX (e.g., BMK, MN15). It also includes range-separated hybrids (CAM-B3LYP, LC-BLYP). Similar error profiles of vertical energy were obtained for both dye groups, although the errors related to hydroxyphenylimidazopiridines are significantly larger. Overall, functionals including 40-55\% of EEX (SOGGA11-X, BMK, M06-2X) ensure satisfactory agreement with the reference vertical excitation energies obtained using the RI-CC2 method; however, MN15 significantly outperforms them, providing a mean absolute error of merely $0.04 \mathrm{eV}$ together with a very high correlation coefficient $\left(R^{2}=0.98\right)$. Within the investigated set of functionals, there is no single functional that would equally accurately determine ground- and excited-state dipole moments of difluoroboranes and hydroxyphenylimidazopiridine derivatives. Depending on the chosen set of dyes, the most accurate $\mu_{\mathrm{GS}}$ predictions were delivered by MN15 incorporating a major EEX contribution (difluoroboranes) and by PBE0 containing a minor EEX fraction (hydroxyphenylimidazopiridines). Reverse trends are observed for $\mu_{\mathrm{ES}}$, i.e., for difluoroboranes the best results were obtained with functionals including a minor fraction of EEX, specifically PBE0, while in the case of hydroxyphenylimidazopiridines, much more accurate predictions were provided by functionals incorporating a major EEX contribution (BMK, MN15).

Keywords: TD-DFT; ab initio; fluorescent dyes; vertical energy; dipole moments

\section{Introduction}

Unceasing development of various technologies entails an increasing demand for fluorescent dyes meeting strictly defined criteria. The fluorophore motif incorporated in the structure of these molecules allows their potential use as biomarkers, fluorescent probes, laser dyes, or in the construction of organic light-emitting diodes. In the context of biomedical applications, the most valuable fluorescent dyes display absorption/emission bands shifted into the near-infrared range. Those so-called NIR dyes are used in numerous medical imaging techniques, such as FACS (Fluorescence-Activated Cell Sorting) [1-3], FLIM (Fluorescence-Lifetime Imaging Microscopy) [4-6], or FIGS (Fluorescence ImageGuided Surgery) [7-9]. Fluorescent dyes can be also used in imaging techniques benefiting from the two-photon absorption phenomenon [6,10-13]. In particular, special attention is paid to two-photon scanning laser microscopy, which became a breakthrough in bioimaging 
techniques $[14,15]$. Currently, the effort of many research groups is directed towards designing fluorescent dyes for specific applications, e.g., for monitoring the biological functions of organs [16-18], the detection of ions in living organisms [19-21], or for the analysis of the causes of neurodegenerative diseases [22-25].

There are numerous classes of fluorescent dyes, but difluoroboranes (see Figure 1, left panel) are one of the most widely employed because of their exceptional photophysical properties, such as a remarkably high fluorescence quantum yield and photostability. Their additional advantage is the ease of functionalization. Owing to the above properties, difluoroboranes have been used as optical switches [26-31], fluorescent probes [32-38], photosensitizers used in photochemotherapy [39-45], biomarkers [46-50], and TADF (ThermallyActivated Delayed Fluorescence) materials used for emitters for organic light-emitting diodes [51-54], among others.

Hydroxyphenylimidazopiridine derivatives (hereafter referred as HPIPs, (see Figure 1, right panel)) are yet another class of unique dyes because they can show ESIPT (ExcitedState Intramolecular Proton Transfer) in both polar and nonpolar solvents, and what is even more distinctive, is that ESIPT-related emission occurs from the stable zwitterion form. Another interesting feature that some of these dyes present is so-called dual emission, in other words, the ability to simultaneously emit from two different conformers/tautomers (in two different spectral ranges). ESIPT dyes are particularly promising candidates for medicine $[40,55,56]$, fluorescent probes [57-59], molecular logic gates [60-62], chemical sensors [63-65], photostabilizers [66-68], laser dyes [69-72] and white light-emitting material [73-76] applications, since they are characterized by unusually large Stokes shifts (exceeding even $5000 \mathrm{~cm}^{-1}$ ). This is indeed an extremely desirable feature for fluorescent dyes, as it leads to negligible overlapping of absorption and emission spectra, which in turn, prevents the emitted photons from being reabsorbed, a phenomenon that often plagues the applications of emissive dyes in biological media as well as in materials.<smiles>[R]C1=C(C)C[Z](F)B(F)N1CC</smiles>

\section{$\mathrm{Z}=\mathrm{O}$ or $\mathrm{S}$, $\mathrm{R}=\mathrm{CH}$ or $\mathrm{N}$}<smiles>[Y]C(C)=C(C)C(C)=NCC</smiles>

$\mathrm{Y}=\mathrm{O}$ or $\mathrm{N}$

Figure 1. Structural motifs of difluoroboranes (left) and hydroxyimidazopiridine (right) derivatives.

It should be highlighted that electronic structure theories can provide valuable insight into the absorption and emission of radiation, enabling a deep understanding of excited-state properties [77-82], which are of pivotal importance for applications in many technological sectors. Indeed, the calculations of the excited-state properties are performed not only to gain insight into absorption, fluorescence, and phosphorescence processes, but also to model the fundamental aspects of energy conversion phenomena, such as those exploited in solar cells [83-89]. In particular, electronic structure calculations may play a key role in tailoring the specific properties of difluoroborane and HPIP dyes needed for the above applications, provided accurate approaches are used. Undoubtedly, time-dependent density functional theory (TD-DFT) is the most widely used theoretical approach enabling computation of the optical signatures and excited-state properties of dyes [81,90-96]. Owing to $\mathrm{N}^{4}$ scaling, at first glance, it seems a cost-effective choice for medium- and large-sized dyes such as the ones mentioned above. However, the predictive power of popular density functional approximations in determining excited-state properties for these two interesting classes of dyes is largely unknown, therefore this study aims at filling this gap. Originally, the TD-DFT method was proposed by Runge and Gross [97]. However, the true milestone for practical 
applications was the famous Casida's equation, developed 10 years later [98]. Introducing this effective linear-response formalism into TD-DFT granted a significant advancement of efficiency, making it possible to solve TD Schrödinger equations for many compounds. Unceasing efforts are made towards additional performance improvements and expanding the applicability of this method. Nevertheless, the predictive power of TD-DFT in terms of evaluating the properties of molecules in their excited states largely depends on the selected exchange-correlation functional and the nature of the excited state itself $\left(\pi \rightarrow \pi^{*}, n \rightarrow \pi^{*}\right.$, charge transfer, double excitation, valence, Rydberg, singlet, triplet, etc.). To date, none of the proposed functionals can satisfactorily anticipate a wide number of properties. In this context, the true breakthrough was the introduction of so-called range-separated hybrids (RSHs), which, unlike the previously known LDA, GGA, and mGGA DFAs, are functionals including a certain fraction of the exact exchange energy related to the distance between electrons. RSHs offer significantly improved accuracy for such troublesome cases as the description of charge-transfer (CT) states [99-104]. The reason behind the significant enhancement of estimations associated with CT states lies behind employing Ewald's split of the Coulombic electron-electron interaction operator, allowing for the introduction of the dependency of the EEX contribution on the distance between electrons. Consequently, such an approach enables introducing the correction of long-range interactions (directly related to a proper description of CT states). This scheme was proposed by Tawada, Hirao and co-workers [101] and practically utilized by Yanai, Tew and Handy who developed the most known RSH functional-CAMB3LYP [105]. Other popular RSH functionals are frequently denoted as "LC-" (long-range corrected) DFAs, i.e., LC-BLYP [106] and LC- $\omega$ PBE [107], while another popular subgroup consists of Head-Gordon's $\omega$ B97 functionals $[108,109]$. The second major step was proposing so-called double hybrids [110-113], which allows to mitigate the other known TD-DFT setback, namely, the characterization of states with a double-excited nature. In particular, these DFAs include the dependency of the exchange correlation energy of DFA on virtual Kohn-Sham orbitals, where the exchange and correlation energy terms encompass a certain fraction of the Hartree-Fock exchange, and the correlation is additionally mixed with the perturbative second-order correlation part [111]. Unfortunately, CIS(D)-like correction implies a significant increase in the computational requirements for medium and large molecules.

As can be seen, getting insight into excited-state properties exploiting TD-DFT might be quite a challenge. Therefore, to estimate the accuracy of TD-DFT predictions, one should depend on one of the two existing validation schemes described below. These validation methods are clearly important because most of the DFAs have been designed and parameterized to reproduce the properties of the ground state, not the excited state. Thus, not all DFAs are suitable for reproducing the optical properties of molecules, which in turn, significantly limits their field of application.

The first validation approach benefits from the available experimental data. Indeed, the correct reproduction of experimental data is clearly desirable for most practical applications (i.e., comparison of the experimentally determined Absorption-Fluorescence Crossing Point, AFCP with computed $\left.\mathrm{E}_{0-0}\right)$. However, in the case of the assessment of computational methods, this approach is not always optimal, since error compensation can occur due to a number of effects (i.e., interaction of the molecule with the environment, vibrational effects, etc.), thus leading to accidental agreement with the experimental data. In addition, some experimental data, like excited-state dipole moments can only be deduced indirectly (i.e., by studying solvatochromic effects and using simplified models to extrapolate results), while spectra (absorption and/or emission) in the gas phase are rarely available, meaning their use as an "absolute" benchmark is rather questionable.

The second validation scheme involves comparing TD-DFT results with predictions of more sophisticated ab initio methods, typically based on the wave function, e.g., EOMCCSD [114,115], CAS-SCF/CAS-PT2 [116,117], or CC3 [118-120], which allow to describe the electronic structure of chemical compounds with high precision. Unfortunately, the application of these methods is quite restricted, on one hand by the relatively small molecular systems size $(<20-30$ atoms), since the price of their high accuracy is a tremendous calcula- 
tion cost, and on the other hand by the quite limited accessibility of the key properties [121]. Hence, whenever the subjects under study are larger systems and/or electron-density related properties, the list of feasible methods basically shortens to $\operatorname{ADC}(2)[122,123]$, or CC2 $[124,125]$. Both aforementioned methods are characterized with typical errors within the range of $0.1-0.2 \mathrm{eV}$, which is very reasonable taking into account their $N^{5}$ scaling [121]. Importantly, a comparison with ab initio methods allows to correlate the data obtained by applying an identical computation model (e.g, exact geometry, basis set, environmental model, etc.) to the physical phenomenon.

Certainly, the excitation energy is the most common property used to benchmark TD-DFT. Within the schemes enabling the calculation of excitation energy, two different approaches should be highlighted. The first one, which is still the most common when large molecules are studied, encompasses the calculation of so-called vertical energy, $\mathrm{E}_{\mathrm{vert}}$, for which the computational cost is very low, since it does not require the examination of the excited state. In terms of benchmarking TD-DFT predictive power, $\mathrm{E}_{\mathrm{vert}}$ can be freely compared with values obtained with other, i.e., more sophisticated quantum-chemical methods; however, it does not correspond to a real absorption process, by means of the absorption maximum, $\lambda_{\mathrm{abs}, \max }$. Nevertheless, $\mathrm{E}_{\mathrm{vert}}$ may be a very useful tool, when designing/examining a homologous series of dyes is considered. The second procedure-the adiabatic approach - allows to compute vibrationally resolved optical spectra (at least under harmonic approximation), where the computed adiabatic energy, $\mathrm{E}_{0-0}$, corresponds to the absorption-fluorescence crossing point, AFCP. This scheme allows for a somewhat meaningful correlation between theoretical predictions and experimentally determined data, although, as was underlined above, the straightforward evaluation of the predictive power of DFAs based on experimental data is rather disputable. Another issue is the inclusion of environmental effects into the computation, which requires the choice of a proper solvatation model, i.e., the selection of the equilibrium model is justified when the ground-state or relaxed excited-state dipole moments are evaluated; however, this model does not reflect the physics of the ultrafast absorption process. Thus, a proper examination of the Franck-Condon region of the excited state requires a nonequilibrium solvatation model. To date, many excellent studies concerning TD-DFT applicability in calculating excited-state properties can already be found in the literature. The most prominent ones enclosing benchmarks and reviews regarding the excitation energy, have been provided in the past years by Jacquemin and co-workers [94,126-129] as well as Caricato [130], Thiel [131], Grimme [132,133], Tozer [134] and Truhlar [135-137].

The dipole moment is a quantitative measure of the distribution of electron density, thus its change as a result of radiation absorption is directly related to the nature of the electron transitions observed (e.g., a large change in the dipole moment during electron excitation may indicate that intramolecular charge transfer occurs). In addition, the magnitude of the dipole moment also defines the strength of the molecule's interaction with other molecules, as well as with an external electric field. Hence, the electrical properties of the molecules, such as their dipole moment or polarizability, ensure one of the most direct relationships between the electronic structure of the molecules and the spectroscopically observed quantities, making them the right properties to assess the accuracy of computational methods. It should be emphasized that, unlike electron density, which is a function of coordinates in the selected coordinate system, the dipole moment is an easy to calculate property and convenient to evaluate the predictive power of DFAs in assessing asymmetry in the electron density distribution. Despite the ease of this computational routine, the number of extensive dipole moment $\left(\mu_{\mathrm{GS}}\right.$ or $/$ and $\mu_{\mathrm{ES}}$ or / and the excess dipole moment) benchmarks is rather scarce $[100,138-144]$. It should be stressed that although in the literature one may find a fair number of works focusing on the estimation of excitation energy as well as some studies on dipole moments, the subjects of the vast majority are 'model' small organic compounds. What is even more striking, the number of investigated molecules in most works rarely exceeds 30 , usually highly specific compounds, whereas the number of included DFAs scarcely ever exceeds three. 
Another subject to tackle is the constant development of new functionals, which entails the necessity of assessing their predictive power and comparing them with other already known DFAs.

As can be seen from the above literature survey, there are still some blank pages to be filled. In particular, as already highlighted in the preceding paragraph, the predictive power of popular density functional approximations in predicting excited-state properties for HPIPs and difluoroboranes is largely unknown, which prohibits using TD-DFT with confidence for designing new derivatives with tailored properties. Hence, to overcome these limitations, this study focuses on a large set of molecules encompassing 85 'real-life' dyes originating from two important classes of fluorescent dyes, difluoroboranes and HPIPs. The common denominator of the above dyes is a D- $\pi$-A structural core. The first set benefits from incorporating a $\mathrm{BF}_{2}$ group which stabilizes the six-membered ring, while the latter set introduces intramolecular hydrogen bonding enabling ESIPT. Described fluorescent dyes are investigated using 18 DFAs that can be divided into functionals without EEX (e.g., BLYP, M06-L), with a small contribution of EEX (e.g., BLYP, PBE0), with a major fraction of EEX (e.g., MN15, M06-HF) and RSHs (e.g., CAM-B3LYP, $\omega$ B97X-D). In more detail, the unique aim of this work is to provide reliable data regarding the evaluation of the predictive power of DFAs in terms of the two most important excited-state properties (excitation energy and dipole moments), facilitating the modeling of fluorescent dyes. Since identical geometries and theory levels were used for vertical energy and dipole moment calculations, the presented data allow to directly define the relation between the DFA accuracy in estimating energetic and electron density-related properties. This is particularly important, considering that the only other TD-DFT study dedicated to benchmarking vertical energy and dipole moments on the very same theory level was done by Silva-Junior, Thiel and co-workers $[131,145]$. It should be mentioned that within the chosen set, several dyes exhibit charge transfer during excitation, which is a well-known issue of the TD-DFT approach. Within the chosen DFA set, there are MN15 and APF-D, which were the objects of very few benchmarks/reviews previously $[135,146,147]$, thus their accuracy in predicting the spectroscopic properties of fluorescent dyes is yet to be determined.

\section{Materials and Methods}

All DFT and TD-DFT calculations were performed using the Gaussian 16 (B.01) program package [148], whereas CC2 calculations were executed using the Turbomole code [149]. Firstly, all 85 structures were optimized in the gas phase using B3LYP [150] and the cc-pVDZ basis set [151]. The optimization threshold was improved to $10^{-5}$ a.u. on average residual forces, whereas a self-consistent field convergence criterion was tightened to $10^{-8}$ a.u. In the above computations, the so-called ultrafine-pruned $(99,590)$ integration grid was applied. For all the examined structures, Hessian calculations confirmed that the designated stationary points are the actual minima on the potential energy hypersurface. In the next step, the optimized structures were used to calculate the electronic structure to determine the spectra of one-photon absorption and dipole moments in the ground state and the Franck-Condon region. Excitation energies as well as dipole moments were determined using 18 different correlation-exchange functionals (SVWN [152,153], BLYP [150,154], TPPSh [155], B3LYP [156], X3LYP [157], CAM-B3LYP [105], LC-BLYP [106], APF-D [158], PBE0 [90,159], M06 [137], M06-L [160], M06-HF [161], M06-2X [137], SOGGA11-X [162], BMK [163], MN15 [135], $\omega$ B97X [109], $\omega$ B97X-D, [109]) and the aug-cc-pVDZ basis set. In the last step the above data was compared with the reference results from the RI-CC2 method (obtained with the aug-cc-pVDZ [151] basis set using the recommended auxiliary function database [164]).

Among the studied functionals, we highlight three of them as particularly important for this benchmark study:

MN15 is the first global hybrid meta-nonseparable gradient approximation (NGA), proposed by the Truhlar group. As the name suggests, in contrast to standard XCF, this class 
of functionals does not rely on the partition of energy into exchange and correlation terms. It is a hybridized version of the local MN15-L functional with 58 parameters. Owing to the training on an extended dataset including a wide range of DFT-challenging properties, the above DFA offers not only a good performance for noncovalent interactions and excitation energies, but also improved energies of multireference systems and barrier heights [135].

SOGGA11-X is a 19-parameter variant of SOGGA11 including $40.15 \%$ of Hartree-Fock exchange, proposed by Peverati and Truhlar. It is the first global hybrid GGA offering correct estimation to the second order, for both exchange and correlation terms; however, since it lacks dependence on the kinetic energy density, it is outperformed by hybrid meta-GGAs, like M06 and M11 [162].

$\omega \mathrm{B} 97 \mathrm{X}-\mathrm{D}$ is a range-separated hybrid $(\mathrm{X}=22.2-100)$ GGA including empirical atom-atom dispersion corrections developed by Head-Gordon and Chai [108]. This 18-parameter functional usually provides satisfactory accuracy for thermochemistry, kinetics, and non-covalent interactions. Owing to reoptimization, $\omega$ B97X-D offers a significantly improved performance for noncovalent interactions over its predecessor, $\omega \mathrm{B} 97 \mathrm{X}$.

\section{Results and Discussion}

Below, we present the results of the calculations performed for the lowest excitations of the isolated molecules (see Figures S1-S3), which were carried out to determine the DFA with the highest predictive power, for both the vertical energy and dipole moments ( $\mu_{\mathrm{GS}}$ and $\mu_{\mathrm{ES}}$ ). The electron density difference plots (together with the charge-transfer diagnostic [91]) predicted with the chosen subset of DFAs for exemplary charge-transfer and local states, are available in ESI Tables S3-S6. All structures of difluoroboranes included within this study were synthesized by the Ośmiałowski group [165-169], while the HPIP set consists of structures reported by Acuña [170], Gryko [171-174], Cossio [175], Araki [176], Shimada [177] and Bajipali [178]. Since, in compounds stabilized by an intramolecular hydrogen bond, proton transfer in the ground state is still possible, it is worth underlining that the all structures shown in SI are stable, ground-state forms. Lastly, it should be emphasized that $\mathrm{BF}_{2}$ carrying molecules are rigid ones with easily visible vibrational features in their absorption and emission spectra $[165,168]$, while for the HPIP family of dyes these are weakly visible [172]. The current benchmark thus encompasses compounds of different rigidity.

To enable a straightforward analysis, all results are presented in the form of various errors (i.e., mean absolute error (MAE), maximum absolute error (MAXAE), root mean square error (RMSE)) and the correlation coefficient $R^{2}$, all determined with respect to the reference method (CC2). Notably, for the sake of a reduction in the computational costs, the $\mathrm{C}_{8} \mathrm{H}_{17}$ substituents attached to some of the extended-HPIPs [174] (i.e., 1-HPIP and 28-HPIP, see ESI Figures S2 and S3), have been replaced with methyl groups. It should be stressed, that the choice of CC2 as a reference method was dictated by the considerable size of the examined fluorescent dyes, as well as the implementation of the analytical calculation of the electron density, enabling the computation of excited-state dipole moments. The latter one is particularly important, since the goal of this study is to provide coherent estimations of DFA excitation energies together with ground-state and excited-state dipole moments. Nevertheless, the authors are fully aware that the CC2 approach is not 'error-free', in fact Thiel pointed out that CC2 vertical energies are quite far from TBEs (Theoretical Best Estimates) [131], nevertheless CC2 results presented a nearly linear correlation with TBEs. Thus, despite known limitations, CC2 can be regarded as a valuable tool for assessing DFA accuracy in real-life molecules, for which sophisticated ab initio methods are unavailable. Moreover, according to the recent work of Loos et. al., the typical errors of the CC2 method vary in the range of $0.1-0.2 \mathrm{eV}$ [121], which nicely correspond to the MAEs $(0.12 \mathrm{eV})$ reported by Thiel and Sauer [179]. In turn, Kozma et. reported much higher errors for two-component molecular complexes displaying CT states $(\mathrm{MSE}=-0.36 \mathrm{eV}$ ) [180]. As far as dipole moments are concerned, Loos and Jacquemin performed the evaluation of the $\mu_{\mathrm{GS}}$ of small molecules, reporting CC2 MAEs of between 
0.09 and $0.12 \mathrm{D}$ (depending on the chosen LR scheme), while ES dipole moments were burdened with MAEs in the range of 0.26-0.67 D [144].

\subsection{Vertical Energies}

Different types of errors determined for the respective DFAs are displayed in Table 1 and Figure 2. At first glance, one can see a clear relationship between the fraction of the energy corresponding to the exact exchange and the predictive power of a DFA (see " $\mathrm{X}$ ", Table 1). Secondly, the error trends of individual functionals are quite similar for both groups of dyes, however, qualitatively larger errors are observed for HPIPs. As expected, among the examined set of DFAs, the largest errors are always observed for 'pure' functionals such as BLYP and SVWN, i.e., the MAE above $0.5 \mathrm{eV}$ for $\mathrm{BF}_{2}$ and over $1.0 \mathrm{eV}$ for HPIP compounds. It should be highlighted that the related correlation coefficients are also completely unsatisfactory $\left(R^{2}\right.$ ca. 0.7). Generally, DFAs distinguished by an EEX equal to $0 \%$ or $100 \%$ i.e., all LDA and GGA as well as some RSHs, systematically underestimate the excitation energy (BLYP, M06-L and SVWN) or significantly overestimate it (M06-HF, LC-BLYP). Clearly, the errors yielded by meta-GGA or RSH functionals are less severe then the aforementioned LDA and GGA DFAs. However, even for LC-BLYP, M06-L and M06-HF, MAEs are still rather disappointing (0.3-0.4 eV and 0.5-0.75 eV for $\mathrm{BF}_{2}$ and HPIPs, respectively).

Among the RSH, the most accurate predictions were obtained with CAM-B3LYP, which delivered MAEs not exceeding $0.18 \mathrm{eV}$, while the MAXAEs reached, at most, $0.35 \mathrm{eV}$ for both $\mathrm{BF}_{2}$ and HPIP derivatives. Data presented in Figures S4 and S5 show that CAMB3LYP overestimates (usually $<0.2 \mathrm{eV}$ ) reference excitation energies for both $\mathrm{BF}_{2}$ and HPIP derivatives. Much higher errors concerning the excitation energy were generated by LC-BLYP, which systematically overestimates the excitation energy, i.e., MAEs reaching 0.4 and $0.5 \mathrm{eV}$, respectively for $\mathrm{BF}_{2}$ and HPIPs. This research also included some RSHs designed by Head-Gordon et al., namely, $\omega$ B97X [109] and $\omega$ B97X-D [108]. Both of the aforementioned DFAs overestimate the excitation energy, however the errors provided by $\omega \mathrm{B} 97 \mathrm{X}-\mathrm{D}$ (MAE $\approx 0.20 \mathrm{eV}$ for both dye sets) are clearly lower than for the $\omega \mathrm{B} 97 \mathrm{X}$ counterpart. Interestingly, CAM-B3LYP and $\omega$ B97X-D are among the few DFAs that managed to predict the excitation energies of both dye groups with similar accuracy. APF-D is a functional included in this series that is rarely used to study electronic excited states. Surprisingly, this DFA provides very accurate predictions of the excitation energies of $\mathrm{BF}_{2}$ dyes, with the MAE of only $0.09 \mathrm{eV}$ and a high $R^{2}$, which is the second best result for this series. Nevertheless, the predictions of HPIP excitation energies are burdened with an almost three-times greater MAE $(0.27 \mathrm{eV})$ and a significantly lower correlation coefficient $\left(R^{2}=0.90\right)$, while the MAXAE exceeds $0.40 \mathrm{eV}$.

The most extensive group tested here are hybrid DFAs benefiting from the constant fracture of EEX. For the purposes of this work, they were divided into two subgroups, DFAs containing a minor fraction of EEX (below 30\%, i.e., M06-L, TPSSh, B3LYP, X3LYP, PBE0, M06) and those encompassing a major contribution of EEX (above $40 \%$, i.e., SOGGA11-X, BMK, MN15, M06-2X, M06-HF). In terms of DFAs incorporating the minor EEX contribution, the most underestimated excitation energies were predicted by TPSSh including a small EEX contribution (10\%). Results displayed in Figures S4 and S5 show that in general, hybrid DFAs incorporating a 20\%-30\% EEX fraction (i.e., B3LYP, X3LYP, PBE0, M06), tend to underestimate the excitation energy (ca. $0.1-0.2 \mathrm{eV}$ for the $\mathrm{BF}_{2}$ set and $0.2-0.4 \mathrm{eV}$ for HPIPs). Consequently, identical trends are observed for MAEs, i.e., significantly higher values are provided for HPIPs (in the range of $0.22-0.37 \mathrm{eV}$ ), than for $\mathrm{BF}_{2}$ dyes $(0.07-0.15 \mathrm{eV}$ ). It should be highlighted that the above DFAs deliver very consistent results with a strong linear dependence, i.e., $R^{2}$ oscillating around 0.95 and RMSE in the range of $0.02-0.04 \mathrm{eV}$ for $\mathrm{BF}_{2}$ dyes. Conversely, the mentioned parameters corresponding to HPIPs are considerably worse $\left(R^{2}\right.$ fluctuating around 0.90 and RMSE exceeding $\left.0.10 \mathrm{eV}\right)$. Independently of the dye data set, the best results among this group of DFAs were achieved with PBE0, although MAE and MAXAE related to HPIPs are respectively, two-times and three-times higher than their $\mathrm{BF}_{2}$ counterparts. 
Table 1. DFA errors (in $[\mathrm{eV}]$ ) established for the vertical energy, determined with respect to CC2 results.

\begin{tabular}{|c|c|c|c|c|c|c|c|c|c|c|c|c|c|}
\hline \multirow{2}{*}{ Functional } & \multirow{2}{*}{$X ; \omega$} & \multicolumn{4}{|c|}{$\mathrm{BF}_{2}$} & \multicolumn{4}{|c|}{ HPIP } & \multicolumn{4}{|c|}{ Overall } \\
\hline & & MAE & MAXAE & $R^{2}$ & RMSE & MAE & MAXAE & $R^{2}$ & RMSE & MAE & MAXAE & $R^{2}$ & RMSE \\
\hline SVWN & 0 & 0.54 & 0.98 & 0.70 & 0.31 & 1.02 & 1.40 & 0.49 & 0.72 & 0.86 & 1.40 & 0.24 & 0.79 \\
\hline BLYP & 0 & 0.53 & 0.94 & 0.73 & 0.28 & 1.00 & 1.37 & 0.50 & 0.70 & 0.84 & 1.37 & 0.25 & 0.77 \\
\hline M06-L & 0 & 0.31 & 0.67 & 0.80 & 0.15 & 0.74 & 1.09 & 0.60 & 0.54 & 0.60 & 1.09 & 0.38 & 0.51 \\
\hline TPSSh & 10 & 0.24 & 0.47 & 0.91 & 0.08 & 0.56 & 0.84 & 0.75 & 0.37 & 0.44 & 0.84 & 0.67 & 0.28 \\
\hline B3LYP & 20 & 0.15 & 0.30 & 0.95 & 0.04 & 0.37 & 0.55 & 0.87 & 0.22 & 0.29 & 0.55 & 0.85 & 0.12 \\
\hline X3LYP & 21.8 & 0.12 & 0.27 & 0.96 & 0.03 & 0.32 & 0.49 & 0.89 & 0.19 & 0.26 & 0.49 & 0.87 & 0.10 \\
\hline APF-D & $23 *$ & 0.09 & 0.23 & 0.96 & 0.02 & 0.27 & 0.44 & 0.90 & 0.16 & 0.21 & 0.44 & 0.89 & 0.08 \\
\hline PBE0 & 25 & 0.07 & 0.20 & 0.96 & 0.02 & 0.22 & 0.38 & 0.92 & 0.14 & 0.17 & 0.38 & 0.91 & 0.06 \\
\hline M06 & 27 & 0.09 & 0.20 & 0.95 & 0.02 & 0.28 & 0.38 & 0.93 & 0.14 & 0.21 & 0.38 & 0.90 & 0.08 \\
\hline SOGGA11-X & 40.15 & 0.15 & 0.29 & 0.94 & 0.04 & 0.11 & 0.19 & 0.96 & 0.07 & 0.12 & 0.29 & 0.97 & 0.02 \\
\hline BMK & 42 & 0.13 & 0.22 & 0.96 & 0.03 & 0.11 & 0.20 & 0.96 & 0.07 & 0.12 & 0.22 & 0.98 & 0.02 \\
\hline MN15 & 44 & 0.05 & 0.18 & 0.95 & 0.01 & 0.03 & 0.14 & 0.97 & 0.03 & 0.04 & 0.18 & 0.98 & 0.01 \\
\hline M06-2X & 54 & 0.15 & 0.30 & 0.95 & 0.04 & 0.19 & 0.30 & 0.96 & 0.09 & 0.17 & 0.30 & 0.98 & 0.03 \\
\hline M06-HF & 100 & 0.31 & 0.51 & 0.92 & 0.09 & 0.59 & 0.71 & 0.87 & 0.27 & 0.49 & 0.71 & 0.90 & 0.16 \\
\hline LC-BLYP & $0-100 ; 0.33$ & 0.40 & 0.61 & 0.91 & 0.12 & 0.54 & 0.72 & 0.90 & 0.24 & 0.49 & 0.72 & 0.93 & 0.13 \\
\hline CAM-B3LYP & $19-65 ; 0.33$ & 0.17 & 0.34 & 0.94 & 0.04 & 0.18 & 0.30 & 0.95 & 0.09 & 0.17 & 0.34 & 0.97 & 0.03 \\
\hline$\omega \mathrm{B} 97 \mathrm{X}$ & $15.77-100 ; 0.30$ & 0.31 & 0.53 & 0.90 & 0.10 & 0.40 & 0.57 & 0.92 & 0.18 & 0.37 & 0.57 & 0.95 & 0.08 \\
\hline$\omega \mathrm{B} 97 \mathrm{X}-\mathrm{D}$ & $22.20-100 ; 0.20$ & 0.22 & 0.57 & 0.91 & 0.07 & 0.23 & 0.38 & 0.94 & 0.12 & 0.23 & 0.57 & 0.96 & 0.05 \\
\hline
\end{tabular}

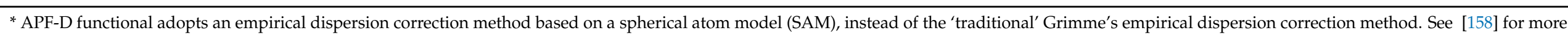
information. 
The data presented in Figure 2 and ESI Figures S4 and S5 clearly indicate, that regardless of the tested dye series, the most accurate excitation-energy predictions are offered by DFAs containing a 40-55\% EEX fraction, i.e., SOGGA11-X, BMK, MN15 and M06-2X. It is worth noting that aside the aforementioned CAM-B3LYP and $\omega$ B97X-D, these are the only DFAs generating quantitatively similar errors for the $\mathrm{BF}_{2}$ and HPIP sets. Most DFAs consisting of 40-55\% EEX, overestimate the excitation energy by ca. $0.1-0.2 \mathrm{eV}$ (except MN15). Consequently, MAEs produced by these DFAs do not exceed $0.2 \mathrm{eV}$ (MAXAEs $<0.3 \mathrm{eV})$, regardless the dye set. Notably, the results of this subgroup of DFAs present a high correlation with the reference for both dye groups $\left(R^{2} \geq 0.94\right)$; however, the RMSEs for HPIPs are ca. two-times higher than their $\mathrm{BF}_{2}$ analogs. Within the 18 functionals examined in this work, the most accurate estimations of excitation energies were provided by the relatively new "Minnesota" family DFA, namely, MN15. This DFA generates the MAE of $0.05 \mathrm{eV}$ for $\mathrm{BF}_{2}$ and only $0.03 \mathrm{eV}$ for HPIP derivatives, while the MAXAEs stay below $0.2 \mathrm{eV}$. Notably, MN15 provides the most consistent results among the examined series, with a $R^{2}$ of 0.95 (0.97) and RMSE equal to $0.01 \mathrm{eV}(0.03 \mathrm{eV})$ for $\mathrm{BF}_{2}$ (HPIP) dyes. In turn, the most overestimated results within DFAs with a major EEX contribution, were provided by M06-HF $(\mathrm{EEX}=100 \%)$, i.e., $\mathrm{MAE}=0.31 \mathrm{eV}$ for $\mathrm{BF}_{2}$ and $\mathrm{MAE}=0.59 \mathrm{eV}$ for HPIPs. Besides that, M06-HF is characterized by a lower $R^{2}(<0.95)$ and RMSE $(\geq 0.09 \mathrm{eV})$ than other functionals in this subgroup.

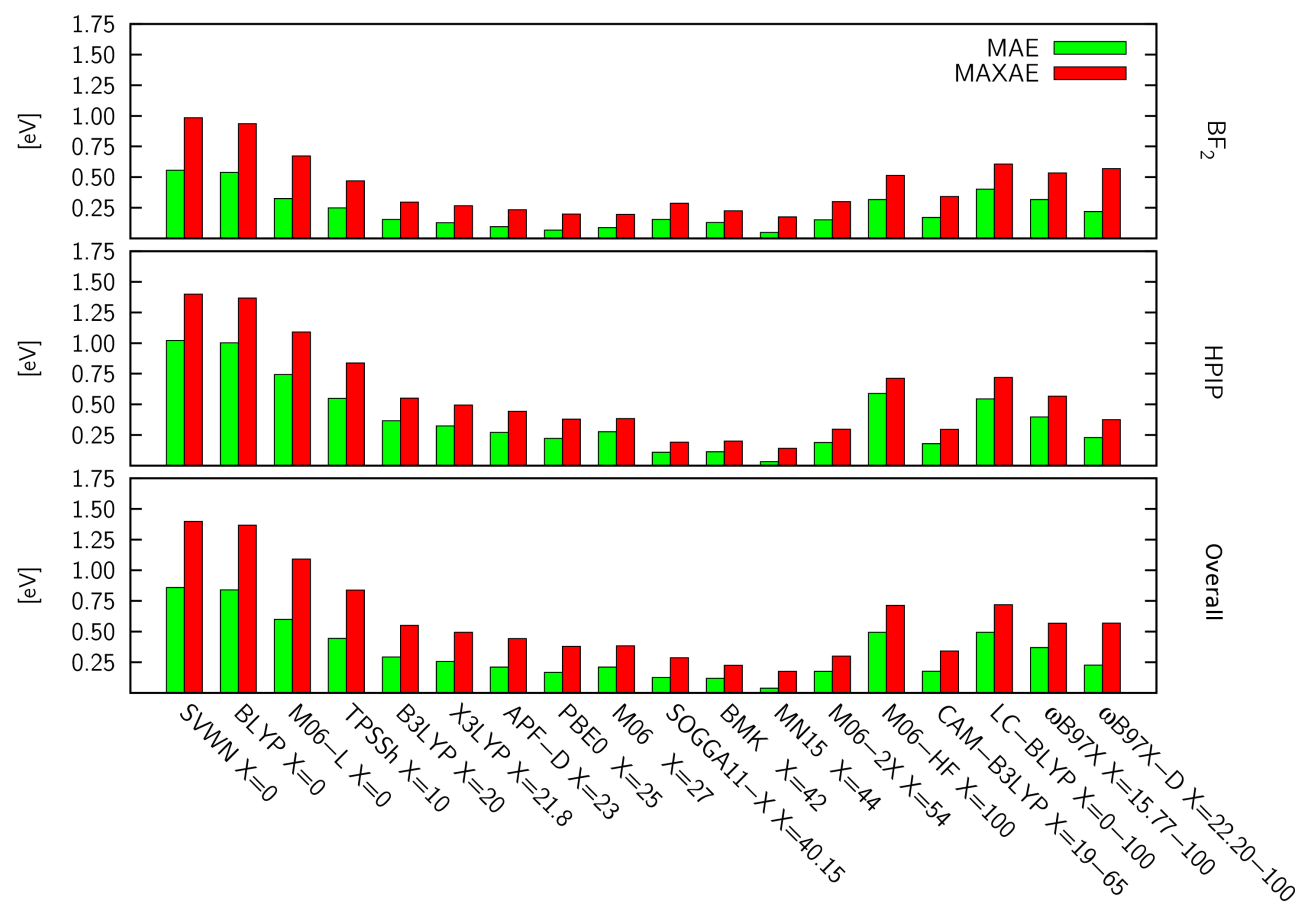

Figure 2. DFA absolute errors established for the excitation energy, determined with respect to CC2.

Lastly, the presented results are in line with previous studies available in the literature. Figure 3 depicts the comparison between MAEs found for fluorescent dyes examined herein and the results reported by Jacquemin and co-workers [126,129]. The aforementioned studies were chosen due to their provision of statistically meaningful data concerning accuracy (i.e., the vast number of examined excitations and a large set of DFAs) as well as comparable (ab initio) reference methods, which enables a straightforward comparison. As can be seen, the error profiles of the compared studies bear many resemblances, although substantial quantitative discrepancies are observed for M06-HF, i.e., the MAE determined with respect to the TBE/TZVP is comparable to the one generated for the HPIP set, while the errors established with respect to the CC methods are almost two-times higher.

A separate matter worth addressing is the accuracy of CC2 (chosen as the reference method herein), as shown by Jacquemin, CC2 delivers qualitatively consistent results with 
CC3, since both error profiles (see yellow and green lines in Figure 3) have an almost identical shape. This proves that CC2 indeed can be used as the reference method for systems too complex for more accurate methods, like CC3. According to the authors best knowledge, the only extensive study concerning MN15 was published in 2016 by the Truhlar team [135]. They reported that MN15 generates the MAE equal to $0.29 \mathrm{eV}$ for the set of valence states included in the EE69 database, which is a considerably higher error than the ones presented within this work.

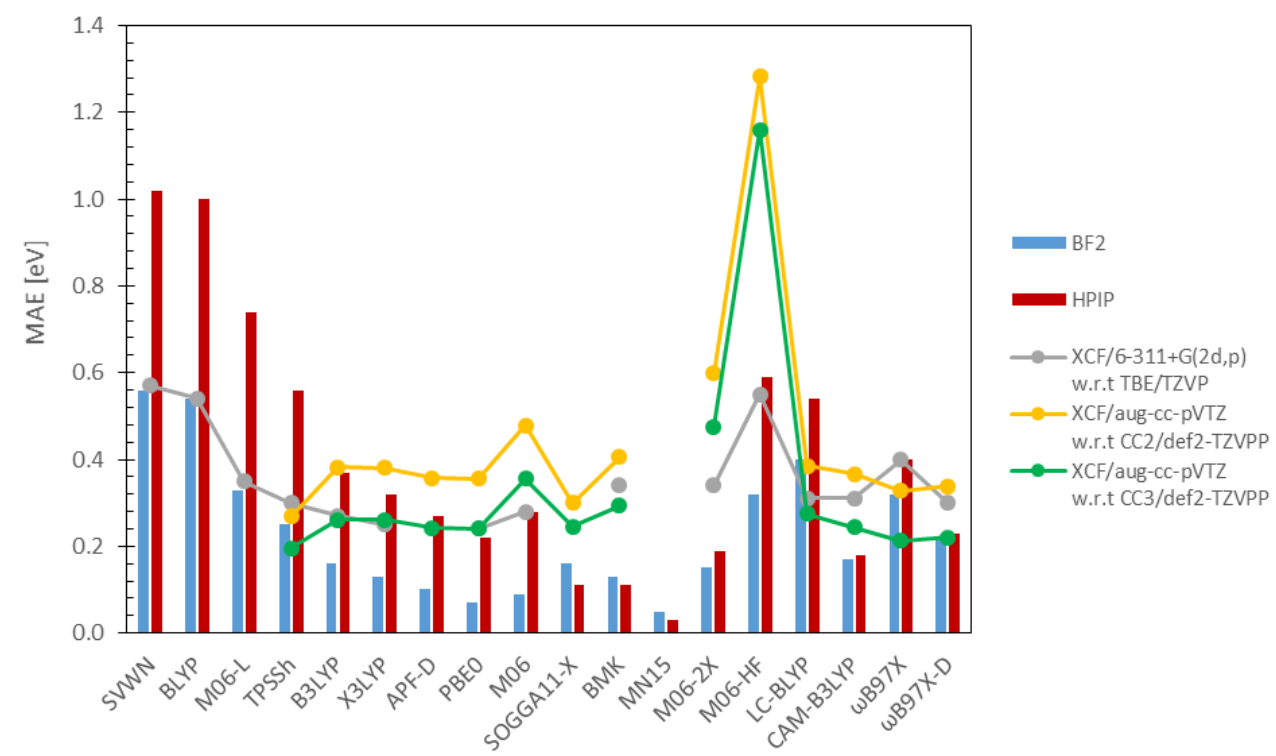

Figure 3. Comparison of DFAs predictive power; data presented in columns concern vertical energies calculated in this work, while the information displayed as "lines" relates to literature data-grey is the Thiel set; yellow, 104 singlet ES [126]; and green, 41 ES of small- and medium-sized organic molecules [129].

\subsection{Dipole Moments}

All data concerning dipole moments are collected in Table 2 and Figure 4. For the sake of avoiding any confusion, the results concerning $\mu_{\mathrm{GS}}$ and $\mu_{\mathrm{ES}}$ (together with the excess dipole moment, $\left.\Delta \mu=\mu_{\mathrm{ES}}-\mu_{\mathrm{GS}}\right)$ will be discussed separately. 
Table 2. DFA errors (in [D]) established for the dipole moments, determined with respect to CC2 results.

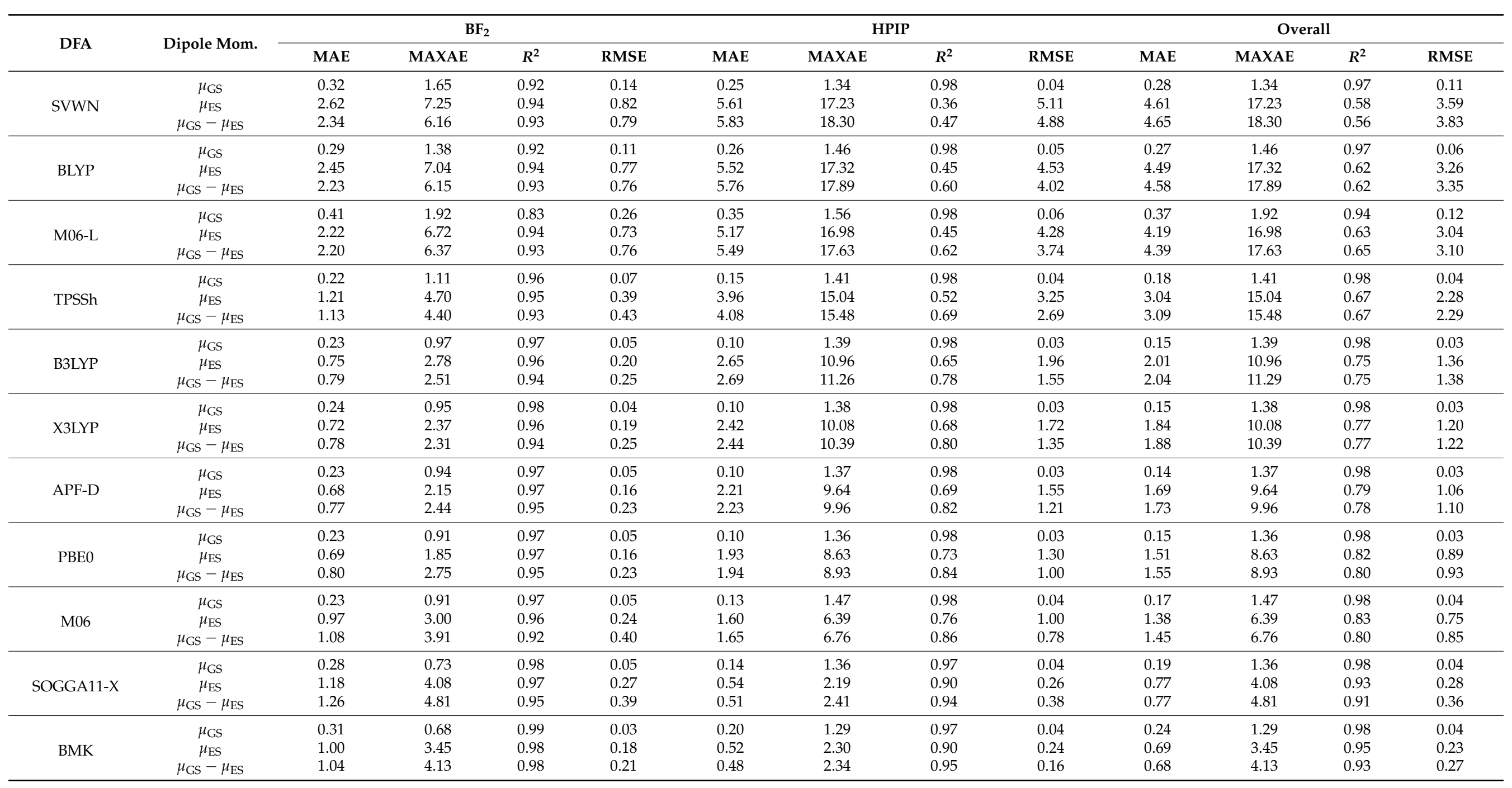


Table 2. Cont.

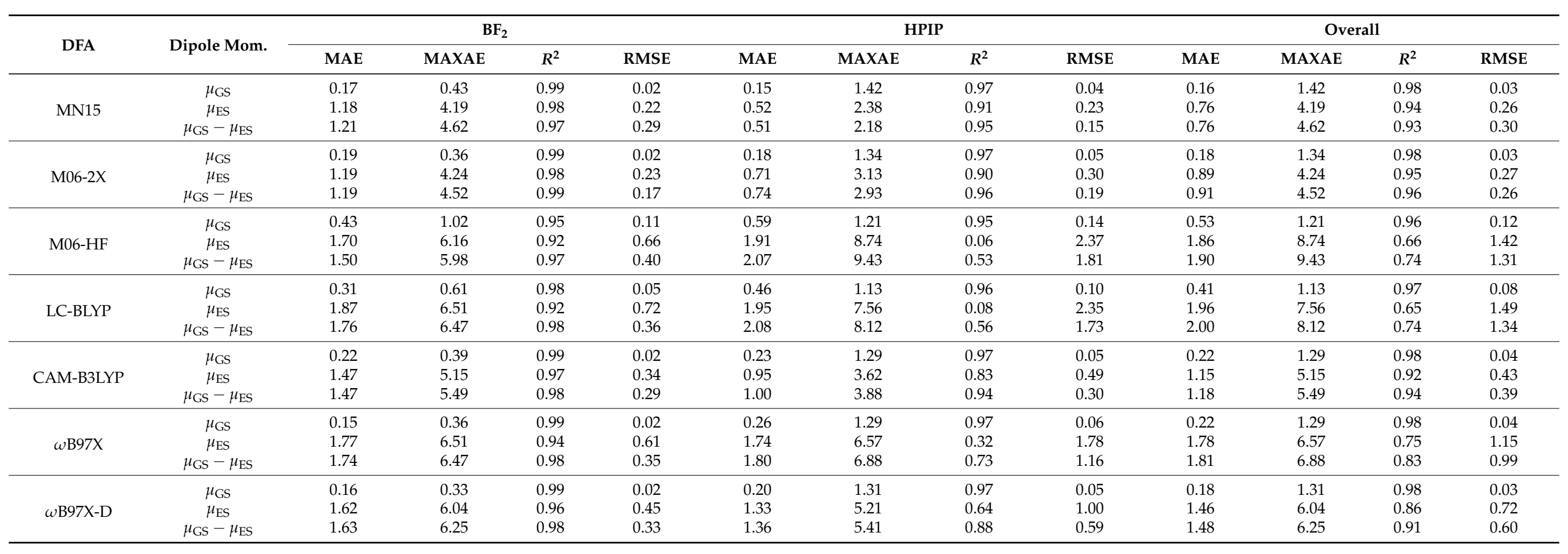



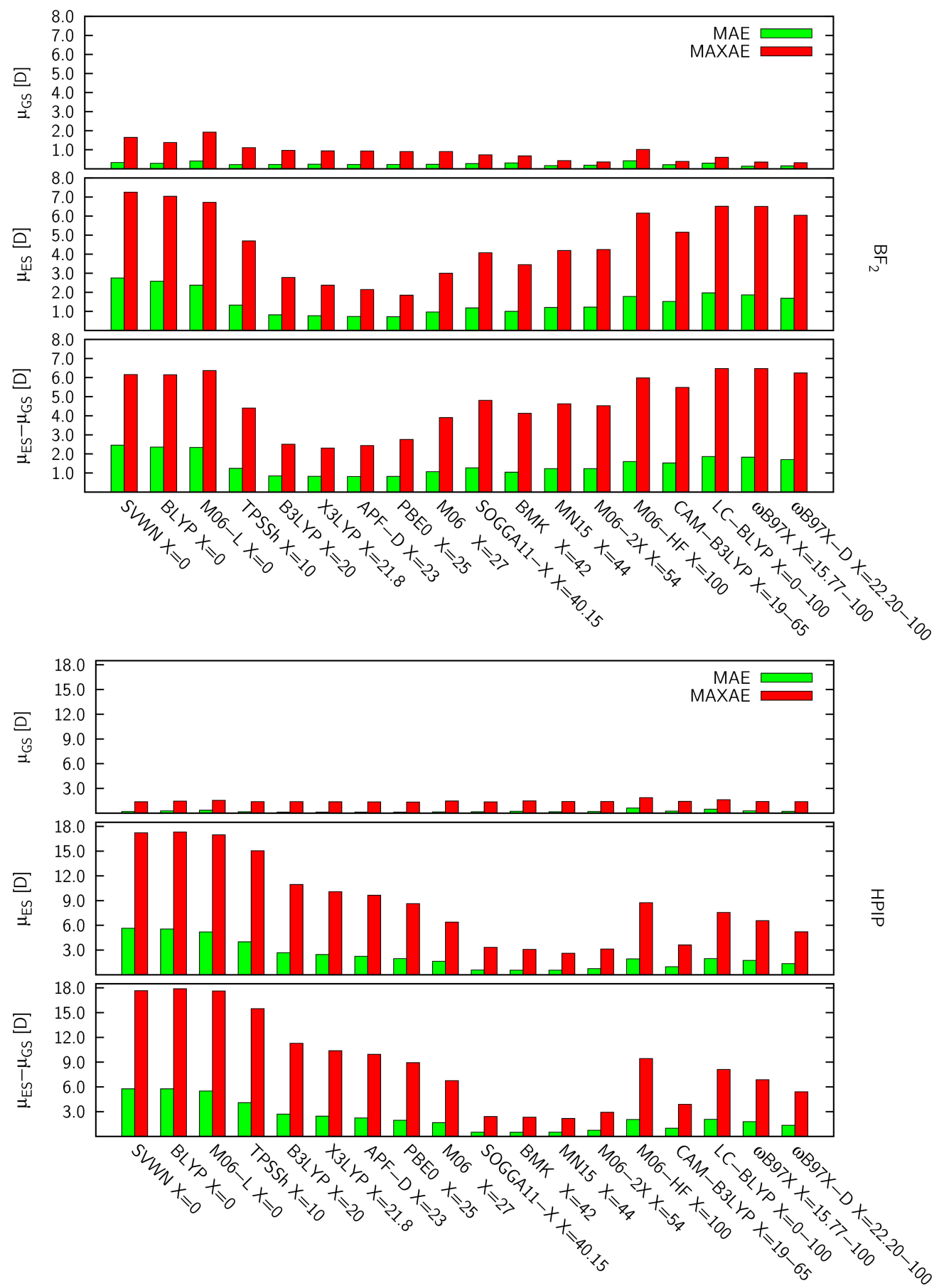

Figure 4. DFA errors established for the dipole moments (determined with respect to CC2).

\subsubsection{Ground-State Dipole Moments}

Generally, DFA predictions of $\mu_{\mathrm{GS}}$ are burdened with rather small MAEs i.e., for both $\mathrm{BF}_{2}$ and HPIP derivatives, the highest errors were generated by M06-HF (MAEs exceeding 0.4 D). However, in terms of the MAXAE, M06-L introduces the highest errors $\left(\mathrm{BF}_{2}\right.$ ca. 2.0 D, HPIP ca. 1.6 D), which in turn manifests in a significantly lower correlation coefficient for $\mathrm{BF}_{2}$ dyes, i.e., $R^{2}=0.82$. Those observations are quite expected since the above 'Minnesota' DFAs, M06-L and M06-HF, are characterized with an EEX $=0 \%$ and $100 \%$, respectively; however, one would anticipate an even weaker accuracy of BLYP and SVWN functionals. Interestingly, BLYP and SVWN predictions present slightly better accuracy and consistency for the HPIP set $(\mathrm{MAE} \approx 0.25 \mathrm{D}, \mathrm{RMSE} \approx 0.05 \mathrm{D})$ than $\mathrm{BF}_{2}$ dyes $(\mathrm{MAE} \approx 0.30 \mathrm{D}, \mathrm{RMSE}>0.1 \mathrm{D})$. 
In turn, all DFAs including 20\%-30\% EEX (B3LYP, X3LYP, APF-D, PBE0, M06) are characterized with a rather similar performance among each set of dyes, i.e., MAE values around $0.23 \mathrm{D}$ and $0.10 \mathrm{D}$ for $\mathrm{BF}_{2}$ and HPIP, respectively. Consequently, the correlation coefficients and RMSEs of these DFAs are the subjects of equally subtle variations. As mentioned above, MAEs related to HPIPs are almost two times lower than the $\mathrm{BF}_{2}$ counterparts, however a reverse trend is observed for MAXAEs. It should be emphasized that the very small differentiation among DFA $\mu_{\mathrm{GS}}$ results, prevents a reliable identification of trends, and thus selection of the best DFA among this subgroup.

In contrast to DFAs containing a minor EEX fraction, results delivered by DFAs incorporating 40\%-55\% EEX (BMK, SOGGA11-X, MN15, M06-2X) differ substantially. For $\mathrm{BF}_{2}$ molecules, $\mathrm{BMK}$ and SOGGA11-X predictions bear similar accuracies (MAE $\approx 0.3 \mathrm{D}$, MAXAE $\approx 0.7 \mathrm{D}$ ), whereas considerably lower errors are obtained with MN15 and M06-2X $(\mathrm{MAE} \approx 0.2 \mathrm{D}, \mathrm{MAXAE} \approx 0.4 \mathrm{D}$ ). On the other hand, MAE (MAXAE) errors generated for HPIPs span across $0.14-0.20 \mathrm{D}(1.29-1.42 \mathrm{D})$ range. Notably, for both dye groups, the smallest MAEs were generated by MN15, which together with M06-2X and CAM-B3LYP, are the only DFAs in the examined series providing similar and yet satisfying accuracy for both $\mathrm{BF}_{2}$ and HPIP dyes.

Among the RSH functionals, the highest mean and maximum errors are related to LC-BLYP (EEX $=0-100 \%$ ) predictions, independently of the examined dye group. In turn, better accuracy is achieved by CAM-B3LYP, which provides almost identical MAEs for HPIP and $\mathrm{BF}_{2}$ (ca. $0.20 \mathrm{D}$ ). For $\mathrm{BF}_{2}$ dyes a superior performance is achieved by $\omega \mathrm{B} 97 \mathrm{X}$ and $\omega \mathrm{B} 97 \mathrm{X}-\mathrm{D}$ DFAs, with a slightly lower mean error generated by $\omega \mathrm{B} 97 \mathrm{X}(\mathrm{MAE}=0.15 \mathrm{D}$, MAXAE $=0.36 \mathrm{D}$ ). While a reverse trend is observed for HPIPs, i.e., $\omega$ B97X-D provides the most accurate prediction among the RSH functionals $(\mathrm{MAE}=0.2 \mathrm{D}, \mathrm{MAXAE}=1.3 \mathrm{D})$. The above trends show clearly that one should be careful in choosing the DFA even for GS parameter calculations. Nevertheless, all DFAs are characterized by very high consistency factors, i.e., $R^{2}>90$ (except M06-L, $\mathrm{BF}_{2}$ ) and RMSEs rarely exceeding $0.1 \mathrm{D}$.

In the literature there are available extensive data treating $\mu_{\mathrm{GS}}$; however, as can be seen from Figure 5, their DFA sets only partially coincide with this study. The most extensive work concerning $200 \mu_{\mathrm{GS}}$ was presented by Hait and Gordon; however the subjects of the mentioned study are small inorganic compounds [143], thus, obviously their $\mu_{\mathrm{GS}}$ values are significantly smaller (see grey line, Figure 5) than the ground-state dipole moments of fluorescent dyes reported here. Nevertheless, one can observe similarities between the error line presented by the Gordon series and the error bars related to the HPIP set; however, the trends for pure DFAs are completely opposite. In the context of this work, more relevant data were reported by Jacquemin, who examined $\mu_{\mathrm{GS}}, \mu_{\mathrm{ES}}$ and excess dipole moments of 30 challenging medium and large organic molecules, dividing them into two series based on the nature of the excitation [142]. As can be seen from Figure 5, DFA predictions computed for $\mathrm{BF}_{2}$ and HPIPs are closely related to the series bearing molecules with a strong $\mathrm{CT}$ nature (green line). 


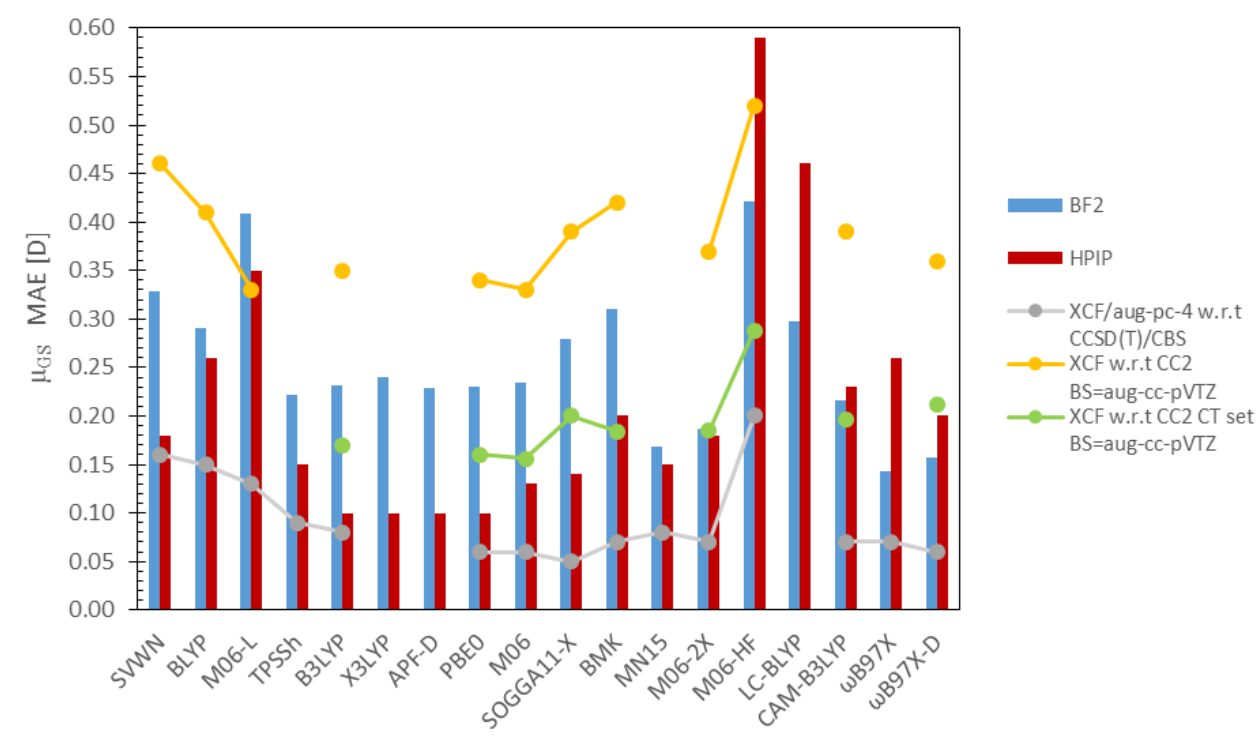

Figure 5. Comparison of DFAs predictive power; data presented in columns concern $\mu_{\mathrm{GS}}$ calculated in this work, while information displayed as "lines" relate to literature data-grey, the database of 200 dipole moments of small inorganic molecules developed by Gordon and Hait [143]; yellow, a set of 15 small organic molecules; and green, 15 large organic molecules exhibiting CT [142].

\subsubsection{Excited-State and Excess Dipole Moments}

Data collected in Table 2 and Figure 4 show clearly that the predictions of $\mu_{\mathrm{ES}}$ (in the Franck-Condon region) are burdened with much larger errors than the corresponding $\mu_{\mathrm{GS}}$, i.e., for most of the investigated DFAs the difference between $\mu_{\mathrm{ES}}$ and $\mu_{\mathrm{GS}}$ errors exceeds one order of magnitude. Of course, this trend was expected, since a large number of the DFAs are parameterized to properly evaluate ground-state properties, not the excited state. Clearly, the magnitude of the $\mu_{\mathrm{ES}}$ errors directly determines the scope of excess dipole moments corresponding to the absorption transition. Consequently, the error profiles of $\mu_{\mathrm{ES}}$ and the related $\Delta \mu$ displayed in Figure 4 , are almost identical. At this point, it should be highlighted that $R^{2}$ and RMSE corresponding to excess dipole moments are directly related to the accuracy of the $\mu_{\mathrm{GS}}$ and $\mu_{\mathrm{GS}}$ components; thus, their straightforward analysis is rather questionable.

As expected, the predictions of pure DFAs (without EEX contribution), i.e., BLYP, SVWN, and M06-L, are burdened with the most severe errors (slightly lighter for M06-L). The above DFAs generate MAEs two-times higher for HPIP (in 5.2-5.6 D range) than $\mathrm{BF}_{2}$ dyes (2.2-2.6 D), and even greater discrepancies are observed for MAXAEs, i.e., BLYP, SVWN and M06-L can overestimate $\mu_{\mathrm{ES}}$ for HPIPs by nearly $20 \mathrm{D}$ (!). Notably, the low correlation factors (0.36-0.45) and high RMSE values (above $4 \mathrm{D}$ ) obtained for the HPIP set demonstrate, that DFAs without EEX are clearly among the worst possible choices for the calculation of density-related properties of challenging molecules exhibiting CT. In turn, the $\mu_{\mathrm{ES}}$ results obtained for $\mathrm{BF}_{2}$ dyes are characterized with $R^{2}$ factors comparable to their $\mu_{\mathrm{GS}}$ counterparts; however, RMSE values related to ES calculations are clearly much higher.

Among all examined DFAs, functionals including a 20-30\% EEX fraction (B3LYP, X3LYP, APF-D, PBE0, M06) predict the $\mu_{\mathrm{ES}}$ of $\mathrm{BF}_{2}$ molecules with greatest accuracy, i.e., MAE values vary in the the range $0.75-0.97 \mathrm{D}$, while MAXAEs do not exceed $3.0 \mathrm{D}$. Additionally, those DFAs provide very consistent results (RMSE $<0.4 \mathrm{D}$ for $\mu_{\mathrm{ES}}$ and excess dipole moments) highly correlated with the reference $\left(R^{2} \geq 0.92\right)$. Amid DFAs containing a minor EEX fraction, the best results were delivered by APF-D and PBE0 (MAE $\approx 0.7 \mathrm{D}$ ), however, PBE0 generated a slightly lower MAXAE ( $<2.0 \mathrm{D})$. In turn, predictions of these DFAs for HPIPs are burdened with a MAE ca. three-times higher (except M06), together with an increased RMSE (1.0-2.0 D except M06) and considerably lower $R^{2}(0.65-0.86)$ 
values. As can be seen, for HPIP dyes, M06 offers considerably better accuracy of $\mu_{\mathrm{ES}}$ values $(\mathrm{MAE}=1.60 \mathrm{D}, \mathrm{MAXAE}=6.4 \mathrm{D})$, than the other examined DFAs with minor EEX contributions.

On the other hand, the smallest deviations for HPIPs were obtained with DFAs containing 40-55\% EEX (SOGGA11-X, BMK, MN15, M06-2X). Indeed, SOGGA11-X, BMK, and MN15 include very similar EEX fractions (40-44\%), which explains their highly coinciding results, i.e., MAEs oscillating around 0.53 D and MAXAEs in the range 2.2-2.4 D. Accordingly, M06-2X including a slightly higher EEX contribution (54\%) generates slightly increased errors (MAE $=0.7 \mathrm{D}$, while MAXAE exceeds $3 \mathrm{D}$ ). Notably, the above functionals provide the best correlation factors $\left(R^{2} \approx 0.9\right)$ and the lowest RMSEs (below $0.3 \mathrm{D}$ ) for HPIPs among all examined DFAs. Similar trends can be extrapolated to $\mathrm{BF}_{2}$ dyes; however, the accuracy of the mentioned DFAs is somewhat lower, i.e., MAEs in the range 1.0-1.2 D and MAXAEs encompassing a 3.5-4.2 D range.

In turn, M06-HF (EEX $=100 \%$ ) predictions for the HPIP set bear a very low $R^{2}$, which implies there is no linear correlation between the M06-HF results and reference values whatsoever. The identical conclusion can be drawn for LC-BLYP estimations of the HPIPs excited-state dipole moments.

Lastly, considering RSHs (LC-BLYP, CAM-B3LYP, $\omega$ B97X, $\omega$ B97X-D), the most accurate results for the both sets of dyes are provided by CAM-B3LYP; however, HPIP predictions are burdened with considerably lower errors $(\mathrm{MAE}=0.95 \mathrm{D}, \mathrm{MAXAE}=3.62 \mathrm{D})$. Unexpectedly, $\omega \mathrm{B} 97 \mathrm{X}$ and $\omega \mathrm{B} 97 \mathrm{X}-\mathrm{D}$ present rather unsatisfactory $R^{2}$ values $(0.3$ and 0.6 , respectively) conjoined with high RMSEs (1.0 D and 1.8 D) for HPIPs, while in comparison their $\mathrm{BF}_{2}$ counterparts display a $R^{2}$ of ca. 0.95 and RMSE below $0.7 \mathrm{D}$.

Literature data used for the comparative analysis are taken from Jacquemin's study mentioned in the preceding paragraph. As can be seen in Figure 6 the highest discrepancies between the $\mu_{\mathrm{ES}}$ predictions reported here and by Jacquemin are related to DFAs without EXX (above $1 \mathrm{D}$ ), which are commonly known for their poor performance. Other predictions are quantitatively similar, although there is not much to be said about the error trends since six of the DFAs examined here were not investigated by Jacquemin.

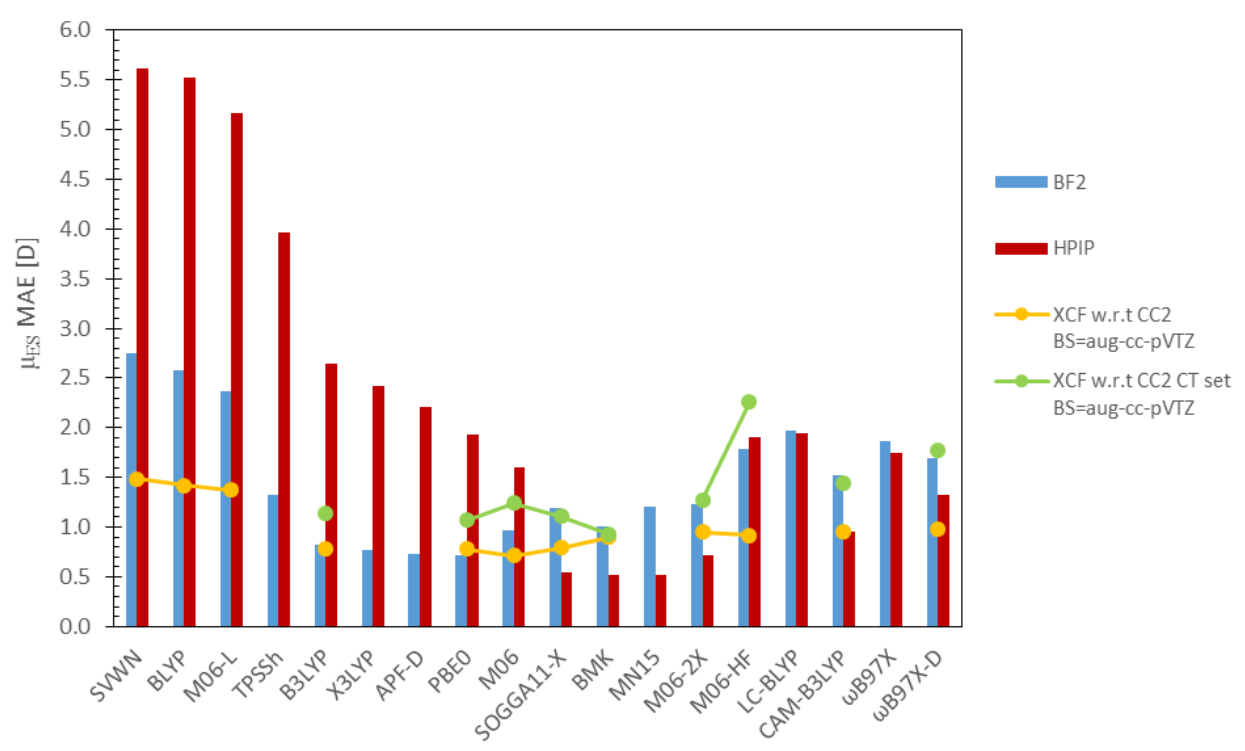

Figure 6. Comparison of DFAs predictive power; data presented in columns concern $\mu_{\mathrm{ES}}$ calculated in this work, while information displayed as "lines" relate to literature data-yellow, a set of 15 small organic molecules and green, 15 large organic molecules exhibiting CT [142].

\section{Conclusions}

The presented study focuses on providing extensive data about TD-DFT predictive power, evaluated for two groups of important dyes encompassing difluoroboranes and 
HPIP derivatives. To ensure statistically meaningful results, the data set compromises 85 molecules manifesting diverse photophysical properties. The emphasis was put on the lowest excitations which in many instances possess a charge-transfer character (see Tables S9 and S10 presenting the values of the $\Lambda$ diagnostic proposed by Peach et al. [134]). The vertical excitation energies and dipole moments ( $\mu_{\mathrm{GS}}, \mu_{\mathrm{ES}}$ and $\left.\Delta \mu\right)$ of the aforementioned dyes were determined by 18 DFAs, with varying contributions of EEX. In particular, this study proves that DFAs incorporating 0-30\% EEX tend to underestimate the excitation energy, while increasing the EEX above $50 \%$ results in a reverse trend. Interestingly, quantitatively similar errors for both dye groups are generated only by DFAs containing $40-50 \%$ of EEX and two RSHs, CAM-B3LYP and $\omega$ B97X-D. For the rest of the examined DFAs, systematically larger errors (MAE and MAXAE) are observed for HPIP derivatives. Within the tested DFA set, the most accurate vertical energy predictions were obtained with MN15 (MAE $\leq 0.05 \mathrm{eV}$ ), which significantly outperforms the second best functional, PBE0 (MAE $=0.22 \mathrm{eV}$ for HPIPs).

A similar analysis performed for dipole moments indicates that within the examined set of DFAs, there is no single functional that would equally accurately determine GS and ES dipole moments of $\mathrm{BF}_{2}$ and HPIP dyes. In the case of $\mu_{\mathrm{GS}}$ the most accurate results were predicted by one of the DFAs with a major EEX fraction, namely MN15 $\left(\mathrm{BF}_{2}\right.$ set) and the DFA with a minor EEX contribution, PBE0 (HPIP set); however, all DFAs incorporating 20-30\% EEX deliver very similar predictions. On the other hand, reverse trends are observed for $\mu_{\mathrm{ES}}$, i.e., for $\mathrm{BF}_{2}$, the best results were obtained with DFAs including a minor fraction of EEX (B3LYP, X3LYP, PBE0, M06 and APF-D), specifically PBE0, while in the case of HPIP derivatives, much more accurate predictions were provided by DFAs with a major EEX contribution, especially MN15.

To sum up, MN15 strongly outperforms other DFAs in terms of determining the excitation energy; however, in the context of dipole moments, there is no single DFA that would equally accurately determine GS and ES dipole moments of $\mathrm{BF}_{2}$ and HPIP derivatives. Nevertheless, analyzing the results for the combined set of dyes (see Overall, Table 2) one can see that MN15 generates the lowest $\mu_{\mathrm{ES}}$ errors together with one of the most accurate $\mu_{\mathrm{GS}}$, therefore this functional should be dedicated to the further study of 'real-life' fluorescent dyes. The other conclusion that can be formulated, is that methods delivering very accurate predictions for smaller molecules can often not be adequate for examining complex real-life dyes. Thus, one should carefully choose the density functional approximation and/or think about a validation scheme suitable for their purpose.

Supplementary Materials: Figure S1: Difluoroborane structures $\left(\mathrm{BF}_{2}\right)$ studied herein, Figures S2 and S3: HPIP structures studied herein, Table S1: Results of CC2 simulations performed in the gas phase- $\mathrm{BF}_{2}$ set, Table S2: Results of CC2 simulations performed in the gas phase-HPIP set, Figure S4: Mean Signed Errors $(\mathrm{eV})$ determined for $\mathrm{BF}_{2}$ dyes excitation energies, with respect to $\mathrm{CC} 2$, Figure S5: Mean Signed Errors $(\mathrm{eV})$ determined for HPIP dyes excitation energies, with respect to CC2, Figure S6: Percentage signed errors established for $\mathrm{BF}_{2}$ dipole moments, with respect to $\mathrm{CC} 2$, Figure S7: Percentage signed errors established for HPIP dipole moments, with respect to CC2, Table S3: Electron density difference plots and related electron transition parameters of the $13-\mathrm{BF}_{2}$ dye, Table S4: Electron density difference plots and related electron transition parameters of the $27-\mathrm{BF}_{2}$ dye, Table S5: Electron density difference plots and related electron transition parameters of the 45-HPIP dye, Table S6: Electron density difference plots and related electron transition parameters of the 13-HPIP dye, Tables S7 and S8: Differences between respective EDD plots, Table S9: $\Lambda$ diagnostic results of the $\mathrm{BF}_{2}$ dyes set, Table S10: $\Lambda$ diagnostic results of the HPIP dyes set.

Author Contributions: Conceptualization, A.M.G. and B.O.; methodology, A.M.G.; software, A.M.G.; validation, A.M.G.; formal analysis, A.M.G.; investigation, A.M.G.; data curation, A.M.G.; writingoriginal draft preparation, A.M.G.; writing-review and editing, A.M.G. and B.O.; visualization, A.M.G.; supervision, B.O.; project administration, A.M.G.; funding acquisition, A.M.G. All authors have read and agreed to the published version of the manuscript.

Funding: This research was funded by the Polish National Science Centre (Grant No. 2017/27/N/ST4/ 01266). 
Institutional Review Board Statement: Not applicable.

Informed Consent Statement: Not applicable.

Data Availability Statement: The data presented in this study are available in this article or the Supplementary Material.

Acknowledgments: A generous allotment of computer time from the Wroclaw Supercomputer and Networking Center is acknowledged.

Conflicts of Interest: The authors declare no conflict of interest.

\section{References}

1. Bonner, W.; Hulett, H.; Sweet, R.; Herzenberg, L. Fluorescence Activated Cell Sorting. Rev. Sci. Instrum. 1972, 43, 404-409. [CrossRef]

2. Cormack, B.; Valdivia, R.; Falkow, S. FACS-Optimized Mutants of the Green Fluorescent Protein (GFP). Gene 1996, 173, 33-38. [CrossRef]

3. Liu, L.; Cheung, T.; Charville, G.; Rando, T. Isolation of Skeletal Muscle Stem Cells by Fluorescence-Activated Cell Sorting. Nat. Protoc. 2015, 10, 1612-1624. [CrossRef] [PubMed]

4. Gadella, T., Jr.; Jovin, T.; Clegg, R. Fluorescence Lifetime Imaging Microscopy (FLIM): Spatial Resolution of Microstructures on the Nanosecond Time Scale. Biophys. Chem. 1993, 48, 221-239. [CrossRef]

5. Bastiaens, P.; Squire, A. Fluorescence Lifetime Imaging Microscopy: Spatial Resolution of Biochemical Processes in the Cell. Trends Cell Biol. 1999, 9, 48-52. [CrossRef]

6. Li, L.L.; Li, K.; Li, M.Y.; Shi, L.; Liu, Y.H.; Zhang, H.; Pan, S.L.; Wang, N.; Zhou, Q.; Yu, X.Q. BODIPY-Based Two-Photon Fluorescent Probe for Real-Time Monitoring of Lysosomal Viscosity with Fluorescence Lifetime Imaging Microscopy. Anal. Chem. 2018, 90, 5873-5878. [CrossRef] [PubMed]

7. Sun, D.; Bloomston, M.; Hinkle, G.; Al-Saif, O.; Hall, N.; Povoski, S.; Arnold, M.; Martin, E., Jr. Radioimmunoguided Surgery (RIGS), PET/CT Image-Guided Surgery, and Fluorescence Image-Guided Surgery: Past, Present, and Future. J. Surg. Oncol. 2007, 96, 297-308. [CrossRef] [PubMed]

8. Vahrmeijer, A.; Hutteman, M.; Van Der Vorst, J.; Van De Velde, C.; Frangioni, J. Image-Guided Cancer Surgery Using Near-Infrared Fluorescence. Nat. Rev. Clin. Oncol. 2013, 10, 507-518. [CrossRef] [PubMed]

9. Sun, Y.; Zeng, X.; Xiao, Y.; Liu, C.; Zhu, H.; Zhou, H.; Chen, Z.; Xu, F.; Wang, J.; Zhu, M.; et al. Novel Dual-Function Near-Infrared II Fluorescence and PET Probe for Tumor Delineation and Image-Guided Surgery. Chem. Sci. 2018, 9, 2092-2097. [CrossRef] [PubMed]

10. Chang, Z.F.; Jing, L.M.; Chen, B.; Zhang, M.; Cai, X.; Liu, J.J.; Ye, Y.C.; Lou, X.; Zhao, Z.; Liu, B.; et al. Rational Design of Asymmetric Red Fluorescent Probes for Live Cell Imaging with High AIE Effects and Large Two-Photon Absorption Cross Sections Using Tunable Terminal Groups. Chem. Sci. 2016, 7, 4527-4536. [CrossRef] [PubMed]

11. Adjili, S.; Favier, A.; Fargier, G.; Thomas, A.; Massin, J.; Monier, K.; Favard, C.; Vanbelle, C.; Bruneau, S.; Peyriéras, N.; et al. Biocompatible Photoresistant Far-Red Emitting, Fluorescent Polymer Probes, with Near-Infrared Two-Photon Absorption, for Living Cell and Zebrafish Embryo Imaging. Biomaterials 2015, 46, 70-81. [CrossRef]

12. Xia, Y.; Zhang, H.; Zhu, X.; Zhang, Q.; Fang, M.; Li, X.; Zhou, H.; Yang, X.; Zhang, X.; Tian, Y. Two-Photon Fluorescent Probe with Enhanced Absorption Cross Section for Relay Recognition of $\mathrm{Zn}^{2+} / \mathrm{P}_{2} \mathrm{O}_{7}^{4-}$ and in Vivo Imaging. Spectrochim. Acta A 2018, 204, 446-451. [CrossRef] [PubMed]

13. Liu, H.W.; Zhu, X.; Zhang, J.; Zhang, X.B.; Tan, W. A Red Emitting Two-Photon Fluorescent Probe for Dynamic Imaging of Redox Balance Meditated by a Superoxide Anion and GSH in Living Cells and Tissues. Analyst 2016, 141, 5893-5899. [CrossRef] [PubMed]

14. Denk, W.; Strickler, J.H.; Webb, W.W. Two-Photon Laser Scanning Fluorescence Microscopy. Science 1990, 248, 73-76. [CrossRef] [PubMed]

15. Benninger, R.K.; Piston, D.W. Two-Photon Excitation Microscopy for the Study of Living Cells and Tissues. Curr. Protoc. Cell Biol. 2013, 59, 4.11.1-4.11.24. [CrossRef]

16. Flusberg, B.A.; Jung, J.C.; Cocker, E.D.; Anderson, E.P.; Schnitzer, M.J. In Vivo Brain Imaging Using a Portable 3.9 gram Two-Photon Fluorescence Microendoscope. Opt. Lett. 2005, 30, 2272-2274. [CrossRef] [PubMed]

17. Barretto, R.P.J.; Ko, T.H.; Jung, J.C.; Wang, T.J.; Capps, G.; Waters, A.C.; Ziv, Y.; Attardo, A.; Recht, L.; Schnitzer, M.J. Time-Lapse Imaging of Disease Progression in Deep Brain Areas Using Fluorescence Microendoscopy. Nat. Med. 2011, 17, 223-228. [CrossRef] [PubMed]

18. Piyawattanametha, W.; Cocker, E.D.; Burns, L.D.; Barretto, R.P.J.; Jung, J.C.; Ra, H.; Solgaard, O.; Schnitzer, M.J. In Vivo Brain Imaging Using a Portable $2.9 \mathrm{~g}$ Two-Photon Microscope Based on a Microelectromechanical Systems Scanning Mirror. Opt. Lett. 2009, 34, 2309-2311. [CrossRef]

19. Schummers, J.; Yu, H.; Sur, M. Tuned Responses of Astrocytes and Their Influence on Hemodynamic Signals in the Visual Cortex. Science 2008, 320, 1638-1643. [CrossRef]

20. Mower, A.F.; Kwok, S.; Yu, H.; Majewska, A.K.; Okamoto, K.I.; Hayashi, Y.; Sur, M. Experience-Dependent Regulation of CaMKII Activity within Single Visual Cortex Synapses in Vivo. Proc. Natl. Acad. Sci. USA 2011, 108, 21241-21246. [CrossRef] 
21. Mittmann, W.; Wallace, D.J.; Czubayko, U.; Herb, J.T.; Schaefer, A.T.; Looger, L.L.; Denk, W.; Kerr, J.N.D. Two-Photon Calcium Imaging of Evoked Activity from L5 Somatosensory Neurons in Vivo. Nat. Neurosci. 2011, 14, 1089-1093. [CrossRef]

22. Allegra Mascaro, A.L.; Sacconi, L.; Pavone, F. Multi-Photon Nanosurgery in Live Brain. Front. Neuroenerg. 2010, 2, 21. [CrossRef]

23. Gómez, C.A.; Fu, B.; Sakadžić, S.; Yaseen, M.A. Cerebral Metabolism in a Mouse Model of Alzheimer's Disease Characterized by Two-Photon Fluorescence Lifetime Microscopy of Intrinsic NADH. Neurophotonics 2018, 5, 1-6. [CrossRef]

24. Clark, T.B.; Ziółkowski, M.; Schatz, G.C.; Goodson, T. Two-Photon and Time-Resolved Fluorescence Spectroscopy as Probes for Structural Determination in Amyloid- $\beta$ Peptides and Aggregates. J. Phys. Chem. B 2014, 118, 2351-2359. [CrossRef] [PubMed]

25. Murugan, N.A.; Zaleśny, R.; Kongsted, J.; Nordberg, A.; Ågren, H. Promising Two-Photon Probes for in Vivo Detection of $\beta$ Amyloid Deposits. Chem. Commun. 2014, 50, 11694-11697. [CrossRef] [PubMed]

26. Aotake, T.; Suzuki, M.; Tahara, K.; Kuzuhara, D.; Aratani, N.; Tamai, N.; Yamada, H. An Optically and Thermally Switchable Electronic Structure Based on an Anthracene-BODIPY Conjugate. Eur. J. Chem. 2015, 21, 4966-4974. [CrossRef]

27. Chen, Y.; Zhao, J.; Guo, H.; Xie, L. Geometry Relaxation-Induced Large Stokes Shift in Red-Emitting Borondipyrromethenes (BODIPY) and Applications in Fluorescent Thiol Probes. J. Org. Chem. 2012, 77, 2192-2206. [CrossRef]

28. Thorat, K.G.; Ray, A.K.; Sekar, N. Modulating TICT to ICT Characteristics of Acid Switchable Red Emitting Boradiazaindacene Chromophores: Perspectives from Synthesis, Photophysical, Hyperpolarizability and TD-DFT Studies. Dyes Pigm. 2017, 136, 321-334. [CrossRef]

29. Deniz, E.; Ray, S.; Tomasulo, M.; Impellizzeri, S.; Sortino, S.; Raymo, F.M. Photoswitchable Fluorescent Dyads Incorporating BODIPY and [1,3]Oxazine Components. J. Phys. Chem. A 2010, 114, 11567-11575. [CrossRef] [PubMed]

30. Gotor, R.; Ashokkumar, P.; Hecht, M.; Keil, K.; Rurack, K. Optical pH Sensor Covering the Range from pH 0-14 Compatible with Mobile-Device Readout and Based on a Set of Rationally Designed Indicator Dyes. Anal. Chem. 2017, 89, 8437-8444. [CrossRef] [PubMed]

31. Mukherjee, S.; Thilagar, P. Fine-Tuning Dual Emission and Aggregation-Induced Emission Switching in NPI-BODIPY Dyads. Eur. J. Chem. 2014, 20, 9052-9062. [CrossRef]

32. Loudet, A.; Burgess, K. BODIPY Dyes and Their Derivatives: Syntheses and Spectroscopic Properties. Chem. Rev. 2007, 107, 4891-4932. [CrossRef]

33. Ziessel, R.; Ulrich, G.; Harriman, A. The Chemistry of Bodipy: A New El Dorado for Fluorescence Tools. New J. Chem. 2007, 31, 496-501. [CrossRef]

34. Xiaohua Li, X.; Gao, X.; Shi, W.; Ma, H. Design Strategies for Water-Soluble Small Molecular Chromogenic and Fluorogenic Probes. Chem. Rev. 2014, 114, 590-659. [CrossRef]

35. Wang, B.; Li, P.; Yu, F.; Song, P.; Sun, X.; Yang, S.; Lou, Z.; Han, K. A Reversible Fluorescence Probe Based on Se-BODIPY for the Redox Cycle Between HClO Oxidative Stress and H2S Repair in Living Cells. Chem. Commun. 2013, 49, 1014-1016. [CrossRef] [PubMed]

36. Kowada, T.; Maeda, H.; Kikuchi, K. BODIPY-Based Probes for the Fluorescence Imaging of Biomolecules in Living Cells. Chem. Soc. Rev. 2015, 44, 4953-4972. [CrossRef]

37. Sivaraman, G.; Iniya, M.; Anand, T.; Kotla, N.G.; Sunnapu, O.; Singaravadivel, S.; Gulyani, A.; Chellappa, D. Chemically Diverse Small Molecule Fluorescent Chemosensors for Copper Ion. Coord. Chem. Rev. 2018, 357, 50-104. [CrossRef]

38. Dziuba, D.; Jurkiewicz, P.; Cebecauer, M.; Hof, M.; Hocek, M. A Rotational BODIPY Nucleotide: An Environment-Sensitive Fluorescence-Lifetime Probe for DNA Interactions and Applications in Live-Cell Microscopy. Angew. Chem. Int. Ed. 2016, 55, 174-178. [CrossRef]

39. Yogo, T.; Urano, Y.; Ishitsuka, Y.; Maniwa, F.; Nagano, T. Highly Efficient and Photostable Photosensitizer Based on BODIPY Chromophore. J. Am. Chem. Soc. 2005, 127, 12162-12163. [CrossRef] [PubMed]

40. Awuah, S.G.; You, Y. Boron Dipyrromethene (BODIPY)-Based Photosensitizers for Photodynamic Therapy. RSC Adv. 2012, 2, 11169-11183. [CrossRef]

41. Kamkaew, A.; Lim, S.H.; Lee, H.B.; Kiew, L.V.; Chung, L.Y.; Burgess, K. BODIPY Dyes in Photodynamic Therapy. Chem. Soc. Rev. 2013, 42, 77-88. [CrossRef] [PubMed]

42. Yang, Y.; Guo, Q.; Chen, H.; Zhou, Z.; Guo, Z.; Shen, Z. Thienopyrrole-Expanded BODIPY as a Potential NIR Photosensitizer for Photodynamic Therapy. Chem. Commun. 2013, 49, 3940-3942. [CrossRef] [PubMed]

43. Abrahamse, H.; Hamblin, M.R. New Photosensitizers for Photodynamic Therapy. Biochem. J. 2016, 473, 347-364. [CrossRef]

44. Zhou, J.; Zhang, Y.; Yu, G.; Crawley, M.R.; Fulong, C.R.P.; Friedman, A.E.; Sengupta, S.; Sun, J.; Li, Q.; Huang, F.; et al. Highly Emissive Self-Assembled BODIPY-Platinum Supramolecular Triangles. J. Am. Chem. Soc. 2018, 140, 7730-7736. [CrossRef] [PubMed]

45. Turksoy, A.; Yildiz, D.; Akkaya, E.U. Photosensitization and Controlled Photosensitization with BODIPY Dyes. Coord. Chem. Rev. 2019, 379, 47-64. [CrossRef]

46. Wang, F.; Zhu, Y.; Zhou, L.; Pan, L.; Cui, Z.; Fei, Q.; Luo, S.; Pan, D.; Huang, Q.; Wang, R.; et al. Fluorescent In Situ Targeting Probes for Rapid Imaging of Ovarian-Cancer-Specific $\gamma$-Glutamyltranspeptidase. Angew. Chem. Int. Ed. 2015, 54, 7349-7353. [CrossRef] [PubMed]

47. Zhou, Z.; Wang, F.; Yang, G.; Lu, C.; Nie, J.; Chen, Z.; Ren, J.; Sun, Q.; Zhao, C.; Zhu, W.H. A Ratiometric Fluorescent Probe for Monitoring Leucine Aminopeptidase in Living Cells and Zebrafish Model. Anal. Chem. 2017, 89, 11576-11582. [CrossRef] 
48. Wang, N.; Chen, M.; Gao, J.; Ji, X.; He, J.; Zhang, J.; Zhao, W. A Series of BODIPY-Based Probes for the Detection of Cysteine and Homocysteine in Living Cells. Talanta 2019, 195, 281-289. [CrossRef]

49. Mizusawa, K.; Takaoka, Y.; Hamachi, I. Specific Cell Surface Protein Imaging by Extended Self-Assembling Fluorescent Turn-on Nanoprobes. J. Am. Chem. Soc. 2012, 134, 13386-13395. [CrossRef] [PubMed]

50. Ashokkumar, P.; Ashoka, A.H.; Collot, M.; Das, A.; Klymchenko, A.S. A Fluorogenic BODIPY Molecular Rotor as an Apoptosis Marker. Chem. Commun. 2019, 55, 6902-6905. [CrossRef]

51. Wang, X.; Li, H.; Wu, X.; Shu, H.; Tian, H.; Tong, H.; Wang, L. Highly Efficient Solution-Processed Thermally Activated Delayed Fluorescence Emitter Based on a Fused Difluoroboron Ketoiminate Acceptor: C/N Switch to Realize the Effective Modulation of luminescence behavior. J. Mater. Chem. C 2021, 14133-14138. [CrossRef]

52. Zhan, L.; Ning, W.; Gong, S.; Xie, G.; Yang, C. Difluoroboron Locking Tactic Enhances Photo- and Electroluminescence of TADF Emitter. Dyes Pigm. 2021, 192, 109392. [CrossRef]

53. Li, H.; Shu, H.; Wang, X.; Wu, X.; Tian, H.; Tong, H.; Wang, L. Orange-Red Thermally Activated Delay Fluorescence Emitters Based on Asymmetric Difluoroboron Chelated Enaminone: Impact of Donor Position on Luminescent Properties. Dyes Pigm. 2021, 184, 108810. [CrossRef]

54. Li, G.; Lou, W.; Wang, D.; Deng, C.; Zhang, Q. Difluoroboron-Enabled Thermally Activated Delayed Fluorescence. ACS Appl. Mater. Interfaces 2019, 11, 32209-32217. [CrossRef]

55. Lv, H.M.; Yuan, D.H.; Liu, W.; Chen, Y.; Au, C.T.; Yin, S.F. A Highly Selective ESIPT-Based Fluorescent Probe for Cysteine Sensing and its Bioimaging Application in Living Cells. Sens. Actuators B. Chem. 2016, 233, 173-179. [CrossRef]

56. Caltagirone, C.; Arca, M.; Falchi, A.M.; Lippolis, V.; Meli, V.; Monduzzi, M.; Nylander, T.; Rosa, A.; Schmidt, J.; Talmon, Y.; et al. Solvatochromic Fluorescent BODIPY Derivative as Imaging Agent in Camptothecin Loaded Hexosomes for Possible Theranostic Applications. RSC Adv. 2015, 5, 23443-23449. [CrossRef]

57. Sedgwick, A.; Sun, X.; Kim, G.; Yoon, J.; Bull, S.; James, T. Boronate Based Fluorescence (ESIPT) Probe for Peroxynitrite. Chem. Comm. 2016, 52, 12350-12352. [CrossRef] [PubMed]

58. Zhao, J.; Ji, S.; Chen, Y.; Guo, H.; Yang, P. Excited State Intramolecular Proton Transfer (ESIPT): From Principal Photophysics to the Development of New Chromophores and Applications in Fluorescent Molecular Probes and Luminescent Materials. Phys. Chem. Chem. Phys. 2012, 14, 8803-8817. [CrossRef]

59. Chen, L.; Park, S.; Wu, D.; Kim, H.; Yoon, J. A Two-Photon ESIPT Based Fluorescence Probe for Specific Detection of Hypochlorite. Dyes Pigm. 2018, 158, 526-532. [CrossRef]

60. Singh, P.; Singh, H.; Bhargava, G.; Kumar, S. Triple-Signaling Mechanisms-Based Three-In-One Multi-Channel Chemosensor for Discriminating $\mathrm{Cu}^{2+}$, Acetate and Ion Pair Mimicking AND, NOR, INH and IMP Logic Functions. J. Mater. Chem. C 2015, 3, 5524-5532. [CrossRef]

61. Wang, L.; Li, Y.; You, X.; Xu, K.; Feng, Q.; Wang, J.; Liu, Y.; Li, K.; Hou, H. An Erasable Photo-Patterning Material Based on a Specially Designed 4-(1,2,2-triphenylvinyl)aniline salicylaldehyde hydrazone Aggregation-Induced Emission (AIE) Molecule. J. Mat. Chem. C 2017, 5, 65-72. [CrossRef]

62. Qin, J.C.; Yang, Z.Y. Fluorescent Chemosensor for Detection of $\mathrm{Zn}^{2+}$ and $\mathrm{Cu}^{2+}$ and its Application in Molecular Logic Gate. J. Photochem. Photobiol. A 2016, 324, 152-158. [CrossRef]

63. Klymchenko, A.S. Solvatochromic and Fluorogenic Dyes as Environment-Sensitive Probes: Design and Biological Applications. Acc. Chem. Res. 2017, 50, 366-375. [CrossRef] [PubMed]

64. Liu, Y.; Feng, G. A Visible Light Excitable Colorimetric and Fluorescent ESIPT Probe for Rapid and Selective Detection of Hydrogen Sulfide. Org. Biomol. Chem. 2014, 12, 438-445. [CrossRef] [PubMed]

65. Sedgwick, A.; Wu, L.; Han, H.H.; Bull, S.; He, X.P.; James, T.; Sessler, J.; Tang, B.; Tian, H.; Yoon, J. Excited-State Intramolecular Proton-Transfer (ESIPT) Based Fluorescence Sensors and Imaging Agents. Chem. Soc. Rev. 2018, 47, 8842-8880. [CrossRef] [PubMed]

66. Catalán, J.; Fabero, F.; Soledad Guijarro, M.; Claramunt, R.; Dolores Santa Maria, M.; de la Concepción, M.; Hernández Cano, F.; Elguero, J.; Sastre, R. Photoinduced Intramolecular Proton Transfer as the Mechanism of Ultraviolet Stabilizers: A Reappraisal. J. Am. Chem. Soc. 1990, 112, 747-759. [CrossRef]

67. Paterson, M.; Robb, M.; Blancafort, L.; DeBellis, A. Mechanism of an Exceptional Class of Photostabilizers: A Seam of Conical Intersection Parallel to Excited State Intramolecular Proton Transfer (ESIPT) in o-hydroxyphenyl-(1,3,5)-Triazine. J. Phys. Chem. A 2005, 109, 7527-7537. [CrossRef] [PubMed]

68. Gong, Y.; Wang, Z.; Zhang, S.; Luo, Z.; Gao, F.; Li, H. New ESIPT-Inspired Photostabilizers of Two-Photon Absorption Coumarin-Benzotriazole Dyads: From Experiments to Molecular Modeling. Ind. Eng. Chem. Res. 2016, 55, 5223-5230. [CrossRef]

69. Kwon, J.E.; Park, S.Y. Advanced Organic Optoelectronic Materials: Harnessing Excited-State Intramolecular Proton Transfer (ESIPT) Process. Adv. Mater. 2011, 23, 3615-3642. doi: 10.1002/adma.201102046. [CrossRef]

70. Zhang, W.; Yan, Y.; Gu, J.; Yao, J.; Zhao, Y. Low-Threshold Wavelength-Switchable Organic Nanowire Lasers Based on ExcitedState Intramolecular Proton Transfer. Angew. Chem. Int. Ed. 2015, 54, 7125-7129. [CrossRef]

71. Tang, B.; Liu, H.; Li, F.; Wang, Y.; Zhang, H. Single-Benzene Solid Emitters with Lasing Properties Based on Aggregation-Induced Emissions. Chem. Comm. 2016, 52, 6577-6580. [CrossRef]

72. Li, J.; Wu, Y.; Xu, Z.; Liao, Q.; Zhang, H.; Zhang, Y.; Xiao, L.; Yao, J.; Fu, H. Tuning the Organic Microcrystal Laser Wavelength of ESIPT-Active Compounds: Via Controlling the Excited Enol* and Keto* Emissions. J. Mater. Chem. C 2017, 5, 12235-12240. [CrossRef] 
73. Padalkar, V.S.; Seki, S. Excited-state Intramolecular Proton-Transfer (ESIPT)-Inspired Solid State Emitters. Chem. Soc. Rev. 2016, 45, 169-202. [CrossRef]

74. Matsumoto, H.; Nishimura, Y.; Arai, T. Fluorescence Sensor with A New ON1-OFF-ON2 Switching Mechanism Using the Excited State Intermolecular Proton Transfer Reaction of An Anthracene-diurea Compound. Photochem. Photobiol. 2017, 93, 1187-1192. [CrossRef]

75. Mancini, D.T.; Sen, K.; Barbatti, M.; Thiel, W.; Ramalho, T.C. Excited-State Proton Transfer Can Tune the Color of Protein Fluorescent Markers. ChemPhysChem 2015, 16, 3444-3449. [CrossRef]

76. Tang, K.C.; Chang, M.J.; Lin, T.Y.; Pan, H.A.; Fang, T.C.; Chen, K.Y.; Hung, W.Y.; Hsu, Y.H.; Chou, P.T. Fine Tuning the Energetics of Excited-State Intramolecular Proton Transfer (ESIPT): White Light Generation in A Single ESIPT System. J. Am. Chem. Soc. 2011, 133, 17738-17745. [CrossRef]

77. Sun, Y.; Zhao, Y.; Liu, X.T.; Ren, A.M.; Feng, J.K.; Yu, X.Q. Theoretical Investigation of the Two-Photon Absorption Properties of 3,6-bis(4-vinylpyridinium) Carbazole Derivatives-New Biological Fluorescent Probes. J. Mol. Model. 2012, 18, $2357-2367$. [CrossRef] [PubMed]

78. Vivas, M.; Silva, D.; Malinge, J.; Boujtita, M.; Zaleśny, R.; Bartkowiak, W.; Ågren, H.; Canuto, S.; De Boni, L.; Ishow, E.; et al. Molecular structure-Optical Property Relationships for a Series of Non-Centrosymmetric Two-Photon Absorbing Push-Pull Triarylamine Molecules. Sci. Rep. 2014, 4, 4447. [CrossRef]

79. Osella, S.; Murugan, N.A.; Jena, N.K.; Knippenberg, S. Investigation into Biological Environments through (Non)linear Optics: A Multiscale Study of Laurdan Derivatives. J. Chem. Theory Comput. 2016, 12, 6169-6181. [CrossRef]

80. Osella, S.; Knippenberg, S. Triggering On/Off States of Photoswitchable Probes in Biological Environments. J. Am. Chem. Soc. 2017, 139, 4418-4428. [CrossRef]

81. Zaleśny, R.; Murugan, N.A.; Tian, G.; Medved, M.; Ågren, H. First-Principles Simulations of One- and Two-Photon Absorption Band Shapes of the Bis(BF2) Core Complex. J. Phys. Chem. B 2016, 120, 2323-2332. [CrossRef]

82. Zaleśny, R.; Szczotka, N.; Grabarz, A.; Ośmiałowski, B.; Jacquemin, D. Design of Two-Photon-Excited Fluorescent Dyes Containing Fluoroborylene Groups. ChemPhotoChem 2019, 3, 719-726. [CrossRef]

83. Li, Y.; Xu, B.; Song, P.; Ma, F.; Sun, M. D-A- $\pi$-A System: Light Harvesting, Charge Transfer, and Molecular Designing. J. Phys. Chem. C 2017, 121, 12546-12561. [CrossRef]

84. Le Bahers, T.; Pauporté, T.; Scalmani, G.; Adamo, C.; Ciofini, I. A TD-DFT Investigation of Ground and Excited State Properties in Indoline Dyes used for Dye-Sensitized Solar Cells. Phys. Chem. Chem. Phys. 2009, 11, 11276-11284. [CrossRef] [PubMed]

85. Sánchez-de Armas, R.; San Miguel, M.Á.; Oviedo, J.; Sanz, J.F. Coumarin Derivatives for Dye Sensitized Solar Cells: A TD-DFT Study. Phys. Chem. Chem. Phys. 2012, 14, 225-233. [CrossRef] [PubMed]

86. Ameline, D.; Diring, S.; Farre, Y.; Pellegrin, Y.; Naponiello, G.; Blart, E.; Charrier, B.; Dini, D.; Jacquemin, D.; Odobel, F. Isoindigo Derivatives for Application in P-Type Dye Sensitized Solar Cells. RSC Adv. 2015, 5, 85530-85539. [CrossRef]

87. Zhang, J.; Zhu, H.C.; Zhong, R.L.; Wang, L.; Su, Z.M. Promising Heterocyclic Anchoring Groups with Superior Adsorption Stability and Improved IPCE for High-Efficiency Noncarboxyl Dye Sensitized Solar Cells: A Theoretical Study. Org. Electron. 2018, 54, 104-113. [CrossRef]

88. He, L.J.; Chen, J.; Bai, F.Q.; Jia, R.; Wang, J.; Zhang, H.X. Fine-Tuning $\pi$-Spacer for High Efficiency Performance DSSC: A Theoretical Exploration with D- $\pi$-A Based Organic Dye. Dyes Pigm. 2017, 141, 251-261. [CrossRef]

89. Gauthier, S.; Guen, F.R.L.; Wojcik, L.; Poul, N.L.; Planchat, A.; Pellegrin, Y.; Level, P.G.; Szuwarski, N.; Boujtita, M.; Jacquemin, D.; et al. Synthesis and Properties of Novel Pyranylidene-Based Organic Sensitizers for Dye-Sensitized Solar Cells. Dyes Pigm. 2019, 171, 107747. [CrossRef]

90. Adamo, C.; Barone, V. Toward Reliable Density Functional Methods without Adjustable Parameters: The PBE0 Model. J. Chem. Phys. 1999, 110, 6158-6170. [CrossRef]

91. Adamo, C.; Bahers, T.L.; Savarese, M.; Wilbraham, L.; García, G.; Fukuda, R.; Ehara, M.; Rega, N.; Ciofini, I. Exploring excited states using Time Dependent Density Functional Theory and density-based indexes. Coord. Chem. Rev. 2015, 304-305, 166-178. [CrossRef]

92. Bloino, J.; Biczysko, M.; Santoro, F.; Barone, V. General Approach to Compute Vibrationally Resolved One-Photon Electronic Spectra. J. Chem. Theory Comput. 2010, 6, 1256-1274. [CrossRef]

93. Irfan, A.; Jin, R.; Al-Sehemi, A.G.; Asiri, A.M. Quantum chemical study of the donor-bridge-acceptor triphenylamine based sensitizers. Spectrochim. Acta A 2013, 110, 60-66. [CrossRef] [PubMed]

94. Jacquemin, D.; Perpète, E.A.; Scuseria, G.E.; Ciofini, I.; Adamo, C. TD-DFT Performance for the Visible Absorption Spectra of Organic Dyes: Conventional versus Long-Range Hybrids. J. Chem. Theory Comput. 2008, 4, 123-135. [CrossRef] [PubMed]

95. Presti, D.; Wilbraham, L.; Targa, C.; Labat, F.; Pedone, A.; Menziani, M.C.; Ciofini, I.; Adamo, C. Understanding AggregationInduced Emission in Molecular Crystals: Insights from Theory. J. Phys. Chem. C 2017, 121, 5747-5752. [CrossRef]

96. Yuan, L.; Lin, W.; Yang, Y.; Chen, H. A Unique Class of Near-Infrared Functional Fluorescent Dyes with Carboxylic-AcidModulated Fluorescence ON/OFF Switching: Rational Design, Synthesis, Optical Properties, Theoretical Calculations, and Applications for Fluorescence Imaging in Living Animals. J. Am. Chem. Soc. 2012, 134, 1200-1211. [CrossRef] [PubMed]

97. Runge, E.; Gross, E. Density-Functional Theory for Time-Dependent Systems. Phys. Rev. Lett. 1984, 52, 997-1000. [CrossRef]

98. Casida, M.E. Recent Advances in Density Functional Methods, Part I; World Scientific: Singapore, 1995; p. 155. 
99. Huang, S.; Zhang, Q.; Shiota, Y.; Nakagawa, T.; Kuwabara, K.; Yoshizawa, K.; Adachi, C. Computational Prediction for Singletand Triplet-Transition Energies of Charge-Transfer Compounds. J. Chem. Theory Comput. 2013, 9, 3872-3877. [CrossRef]

100. Guido, C.A.; Mennucci, B.; Scalmani, G.; Jacquemin, D. Excited State Dipole Moments in Solution: Comparison between State-Specific and Linear-Response TD-DFT Values. J. Chem. Theory Comput. 2018, 14, 1544-1553. [CrossRef]

101. Tawada, Y.; Tsuneda, T.; Yanagisawa, S.; Yanai, T.; Hirao, K. A Long-Range-Corrected Time-Dependent Density Functional Theory. J. Chem. Phys. 2004, 120, 8425-8433. [CrossRef]

102. Stein, T.; Kronik, L.; Baer, R. Reliable Prediction of Charge Transfer Excitations in Molecular Complexes Using Time-Dependent Density Functional Theory. J. Am. Chem. Soc. 2009, 131, 2818-2820. [CrossRef]

103. Guido, C.A.; Cortona, P.; Mennucci, B.; Adamo, C. On the Metric of Charge Transfer Molecular Excitations: A Simple Chemical Descriptor. J. Chem. Theory Comput. 2013, 9, 3118-3126. [CrossRef] [PubMed]

104. Jacquemin, D.; Perpète, E.A.; Ciofini, I.; Adamo, C. Assessment of the $\omega$ B97 Family for Excited-State Calculations. Theor. Chem. Acc. 2011, 128, 127-136. [CrossRef]

105. Yanai, T.; Tew, D.; Handy, N. A New Hybrid Exchange-Correlation Functional Using the Coulomb-Attenuating Method (CAM-B3LYP). Chem. Phys. Lett. 2004, 393, 51-57. [CrossRef]

106. Iikura, H.; Tsuneda, T.; Yanai, T.; Hirao, K. A Long-Range Correction Scheme for Generalized-Gradient-Approximation Exchange Functionals. J. Chem. Phys. 2001, 115, 3540-3544. [CrossRef]

107. Vydrov, O.A.; Scuseria, G.E.; Perdew, J.P. Tests of Functionals for Systems with Fractional Electron Number. J. Chem. Phys. 2007, 126, 154109. [CrossRef]

108. Chai, J.D.; Head-Gordon, M. Long-Range Corrected Hybrid Density Functionals with Damped Atom-Atom Dispersion Corrections. Phys. Chem. Chem. Phys. 2008, 10, 6615-6620. [CrossRef] [PubMed]

109. Chai, J.D.; Head-Gordon, M. Systematic Optimization of Long-Range Corrected Hybrid Density Functionals. J. Chem. Phys. 2008, 128, 084106. [CrossRef] [PubMed]

110. Zhao, Y.; Lynch, B.J.; Truhlar, D.G. Doubly Hybrid Meta DFT: New Multi-Coefficient Correlation and Density Functional Methods for Thermochemistry and Thermochemical Kinetics. J. Phys. Chem. A 2004, 108, 4786-4791. [CrossRef]

111. Grimme, S.; Neese, F. Double-Hybrid Density Functional Theory for Excited Electronic States of Molecules. J. Chem. Phys. 2007, 127, 154116. [CrossRef]

112. Kozuch, S.; Martin, J.M.L. Spin-Component-Scaled Double Hybrids: An Extensive Search for the Best Fifth-Rung Functionals Blending DFT and Perturbation Theory. J. Comput. Chem. 2013, 34, 2327-2344. [CrossRef]

113. Brémond, E.; Ciofini, I.; Sancho-García, J.C.; Adamo, C. Nonempirical Double-Hybrid Functionals: An Effective Tool for Chemists. Acc. Chem. Res. 2016, 49, 1503-1513. [CrossRef]

114. Stanton, J.F.; Bartlett, R.J. The Equation of Motion Coupled-Cluster Method. A Systematic Biorthogonal Approach to Molecular Excitation Energies, Transition Probabilities, and Excited State Properties. J. Chem. Phys. 1993, 98, 7029-7039. [CrossRef]

115. Goings, J.J.; Caricato, M.; Frisch, M.J.; Li, X. Assessment of Low-Scaling Approximations to the Equation of Motion CoupledCluster Singles and Doubles Equations. J. Chem. Phys. 2014, 141, 164116. [CrossRef] [PubMed]

116. Andersson, K.; Malmqvist, P.A.; Roos, B.O.; Sadlej, A.J.; Wolinski, K. Second-Order Perturbation Theory with a CASSCF Reference Function. J. Phys. Chem. 1990, 94, 5483-5488. [CrossRef]

117. Roca-Sanjuán, D.; Aquilante, F.; Lindh, R. Multiconfiguration Second-Order Perturbation Theory Approach to Strong Electron Correlation in Chemistry and Photochemistry. WIREs Comput. Mol. Sci. 2012, 2, 585-603. [CrossRef]

118. Christiansen, O.; Koch, H.; Jørgensen, P. Response Functions in the CC3 Iterative Triple Excitation Model. J. Chem. Phys. 1995, 103, 7429-7441. [CrossRef]

119. Koch, H.; Christiansen, O.; Jørgensen, P.; Sanchez de Merás, A.M.; Helgaker, T. The CC3 Model: An Iterative Coupled Cluster Approach Including Connected Triples. J. Chem. Phys. 1997, 106, 1808-1818. [CrossRef]

120. Paul, A.C.; Myhre, R.H.; Koch, H. New and Efficient Implementation of CC3. J. Chem. Theory Comput. 2021, 17, 117-126. [CrossRef]

121. Loos, P.F.; Scemama, A.; Jacquemin, D. The Quest for Highly Accurate Excitation Energies: A Computational Perspective. J. Phys. Chem. Lett. 2020, 11, 2374-2383. [CrossRef]

122. Schirmer, J. Beyond the Random-Phase Approximation: A New Approximation Scheme for the Polarization Propagator. Phys. Rev. A 1982, 26, 2395-2416. [CrossRef]

123. Schirmer, J.; Trofimov, A.B. Intermediate State Representation Approach to Physical Properties of Electronically Excited Molecules. J. Chem. Phys. 2004, 120, 11449-11464. [CrossRef] [PubMed]

124. Christiansen, O.; Koch, H.; Jørgensen, P. The Second-Order Approximate Coupled Cluster Singles and Doubles Model CC2. Chem. Phys. Lett. 1995, 243, 409-418. [CrossRef]

125. Hättig, C.; Weigend, F. CC2 Excitation Energy Calculations on Large Molecules Using the Resolution of the Identity approximation. J. Chem. Phys. 2000, 113, 5154-5161. [CrossRef]

126. Jacquemin, D.; Wathelet, V.; Perpéte, E.; Adamo, C. Extensive TD-DFT Benchmark: Singlet-Excited States of Organic Molecules. J. Chem. Theory Comput. 2009, 5, 2420-2435. [CrossRef]

127. Jacquemin, D.; Perpète, E.A.; Vydrov, O.A.; Scuseria, G.E.; Adamo, C. Assessment of Long-Range Corrected Functionals Performance for $\mathrm{n} \rightarrow \pi *$ Transitions in Organic Dyes. J. Chem. Phys. 2007, 127, 094102. [CrossRef] [PubMed] 
128. Loos, P.F.; Jacquemin, D. Evaluating 0-0 Energies with Theoretical Tools: A Short Review. ChemPhotoChem 2019, 3, 684-696. [CrossRef]

129. Suellen, C.; Freitas, R.G.; Loos, P.F.; Jacquemin, D. Cross-Comparisons between Experiment, TD-DFT, CC, and ADC for Transition Energies. J. Chem. Theory Comput. 2019, 15, 4581-4590. [CrossRef] [PubMed]

130. Caricato, M.; Trucks, G.W.; Frisch, M.J.; Wiberg, K.B. Electronic Transition Energies: A Study of the Performance of a Large Range of Single Reference Density Functional and Wave Function Methods on Valence and Rydberg States Compared to Experiment. J. Chem. Theory Comput. 2010, 6, 370-383. [CrossRef] [PubMed]

131. Silva-Junior, M.R.; Schreiber, M.; Sauer, S.P.A.; Thiel, W. Benchmarks for Electronically Excited States: Time-Dependent Density Functional Theory and Density Functional Theory Based Multireference Configuration Interaction. J. Chem. Phys. 2008, 129, 104103. [CrossRef]

132. Goerigk, L.; Grimme, S. Assessment of TD-DFT Methods and of Various Spin Scaled CIS(D) and CC2 Versions for the Treatment of Low-Lying Valence Excitations of Large Organic Dyes. J. Chem. Phys. 2010, 132, 184103. [CrossRef]

133. Goerigk, L.; Hansen, A.; Bauer, C.; Ehrlich, S.; Najibi, A.; Grimme, S. A Look at the Density Functional Theory Zoo with the Advanced GMTKN55 Database for General Main Group Thermochemistry, Kinetics and Noncovalent Interactions. Phys. Chem. Chem. Phys. 2017, 19, 32184-32215. [CrossRef]

134. Peach, M.; Benfield, P.; Helgaker, T.; Tozer, D. Excitation Energies in Density Functional Theory: An Evaluation and a Diagnostic Test. J. Chem. Phys. 2008, 128, 44118. [CrossRef] [PubMed]

135. Yu, H.S.; He, X.; Li, S.L.; Truhlar, D.G. MN15: A Kohn-Sham Global-Hybrid Exchange-Correlation Density Functional with Broad Accuracy for Multi-Reference and Single-Reference Systems and Noncovalent Interactions. Chem. Sci. 2016, 7, 5032-5051. [CrossRef]

136. Peverati, R.; Truhlar, D.G. Quest for a Universal Density Functional: The Accuracy of Density Functionals Across a Broad Spectrum of Databases in Chemistry and Physics. Phil. Trans. R. Soc. A 2014, 372, 20120476. [CrossRef]

137. Zhao, Y.; Truhlar, D.G. The M06 Suite of Density Functionals for Main Group Thermochemistry, Thermochemical Kinetics, Noncovalent Interactions, Excited States, and Transition Elements: Two New Functionals and Systematic Testing of Four M06-Class Functionals and 12 other Functionals. Theor. Chem. Acc. 2008, 120, 215-241.

138. Champagne, B.; Perpète, E.A.; Jacquemin, D.; van Gisbergen, S.J.A.; Baerends, E.J.; Soubra-Ghaoui, C.; Robins, K.A.; Kirtman, B. Assessment of Conventional Density Functional Schemes for Computing the Dipole Moment and (Hyper)polarizabilities of Push-Pull $\pi$-Conjugated Systems. J. Phys. Chem. A 2000, 104, 4755-4763. [CrossRef]

139. Furche, F.; Ahlrichs, R. Adiabatic Time-Dependent Density Functional Methods for Excited State Properties. J. Chem. Phys. 2002, 117, 7433-7447. [CrossRef]

140. Hickey, A.L.; Rowley, C.N. Benchmarking Quantum Chemical Methods for the Calculation of Molecular Dipole Moments and Polarizabilities. J. Phys. Chem. A 2014, 118, 3678-3687. [CrossRef]

141. Verma, P.; Truhlar, D.G. Can Kohn-Sham Density Functional Theory Predict Accurate Charge Distributions for Both SingleReference and Multi-Reference Molecules? Phys. Chem. Chem. Phys. 2017, 19, 12898-12912. [CrossRef] [PubMed]

142. Jacquemin, D. Excited-State Dipole and Quadrupole Moments: TD-DFT versus CC2. J. Chem. Theory Comput. 2016, 12, 3993-4003. [CrossRef] [PubMed]

143. Hait, D.; Head-Gordon, M. How Accurate Is Density Functional Theory at Predicting Dipole Moments? An Assessment Using a New Database of 200 Benchmark Values. J. Chem. Theory Comput. 2018, 14, 1969-1981. [CrossRef] [PubMed]

144. Sarkar, R.; Boggio-Pasqua, M.; Loos, P.F.; Jacquemin, D. Benchmarking TD-DFT and Wave Function Methods for Oscillator Strengths and Excited-State Dipole Moments. J. Chem. Theory Comput. 2021, 17, 1117-1132. [CrossRef]

145. Silva-Junior, M.R.; Schreiber, M.; Sauer, S.P.A.; Thiel, W. Benchmarks of Electronically Excited States: Basis Set Effects on CASPT2 Results. J. Chem. Phys. 2010, 133, 174318. [CrossRef] [PubMed]

146. Moore, B.; Charaf-Eddin, A.; Planchat, A.; Adamo, C.; Autschbach, J.; Jacquemin, D. Electronic Band Shapes Calculated with Optimally Tuned Range-Separated Hybrid Functionals. J. Chem. Theory Comput. 2014, 10, 4599-4608. [CrossRef]

147. Fang, C.; Durbeej, B. Calculation of Free-Energy Barriers with TD-DFT: A Case Study on Excited-State Proton Transfer in Indigo. J. Phys. Chem. A 2019, 123, 8485-8495. [CrossRef] [PubMed]

148. Frisch, M.J.; Trucks, G.W.; Schlegel, H.B.; Scuseria, G.E.; Robb, M.A.; Cheeseman, J.R.; Scalmani, G.; Barone, V.; Petersson, G.A.; Nakatsuji, H.; et al. Gaussian 16 Revision B.01; Gaussian Inc.: Wallingford, CT, USA, 2016.

149. TURBOMOLE V7.3 2018, a Development of University of Karlsruhe and Forschungszentrum Karlsruhe GmbH, $1989-2007$. TURBOMOLE GmbH, since 2007. Available online: http:/ / www.turbomole.com (accessed on 9 July 2018).

150. Becke, A.D. Density-Functional Exchange-Energy Approximation with Correct Asymptotic Behavior. Phys. Rev. A 1988, 38, 3098-3100. [CrossRef]

151. Dunning, T.H. Gaussian Basis Sets for Use in Correlated Molecular Calculations. I. The Atoms Boron Through Neon and Hydrogen. J. Chem. Phys. 1989, 90, 1007-1023. [CrossRef]

152. Slater, J.C. Quantum Theory of Molecules and Solids Vol. 4: The Self-Consistent Field for Molecules and Solids. Phys. Today 1974, 27, 49-50. [CrossRef]

153. Vosko, S.H.; Wilk, L.; Nusair, M. Accurate Spin-Dependent Electron Liquid Correlation Energies for Local Spin Density Calculations: A Critical Analysis. Can. J. Phys. 1980, 58, 1200-1211. [CrossRef] 
154. Lee, C.; Yang, W.; Parr, R.G. Development of the Colle-Salvetti Correlation-Energy Formula into a Functional of the Electron Density. Phys. Rev. B 1988, 37, 785-789. [CrossRef] [PubMed]

155. Tao, J.; Perdew, J.P.; Staroverov, V.N.; Scuseria, G.E. Climbing the Density Functional Ladder: Nonempirical Meta-Generalized Gradient Approximation Designed for Molecules and Solids. Phys. Rev. Lett. 2003, 91, 146401. [CrossRef]

156. Becke, A.D. Density-Functional Thermochemistry. III. The Role of Exact Exchange. J. Chem. Phys. 1993, 98, 5648-5652. [CrossRef]

157. Xu, X.; Goddard, W.A. The X3LYP Extended Density Functional for Accurate Descriptions of Nonbond Interactions, Spin States, and Thermochemical Properties. Proc. Natl. Acad. Sci. USA 2004, 101, 2673-2677. [CrossRef] [PubMed]

158. Austin, A.; Petersson, G.A.; Frisch, M.J.; Dobek, F.J.; Scalmani, G.; Throssell, K. A Density Functional with Spherical Atom Dispersion Terms. J. Chem. Theory Comput. 2012, 8, 4989-5007. [CrossRef]

159. Ernzerhof, M.; Scuseria, G.E. Assessment of the Perdew-Burke-Ernzerhof Exchange-Correlation Functional. J. Chem. Phys. 1999, 110, 5029-5036. [CrossRef]

160. Zhao, Y.; Truhlar, D.G. A New Local Density Functional for Main-Group Thermochemistry, Transition Metal Bonding, Thermochemical Kinetics, and Noncovalent Interactions. J. Chem. Phys. 2006, 125, 194101. [CrossRef] [PubMed]

161. Zhao, Y.; Truhlar, D.G. Density Functional for Spectroscopy: No Long-Range Self-Interaction Error, Good Performance for Rydberg and Charge-Transfer States, and Better Performance on Average than B3LYP for Ground States. J. Phys. Chem. A 2006, 110, 13126-13130. [CrossRef]

162. Peverati, R.; Truhlar, D.G. A Global Hybrid Generalized Gradient Approximation to the Exchange-Correlation Functional that Satisfies the Second-order Density-Gradient Constraint and has Broad Applicability in Chemistry. J. Chem. Phys. 2011, 135, 191102. [CrossRef]

163. Boese, A.D.; Martin, J.M.L. Development of Density Functionals for Thermochemical Kinetics. J. Chem. Phys. 2004, 121, 3405-3416. [CrossRef]

164. Weigend, F.; Köhn, A.; Hättig, C. Efficient Use of the Correlation Consistent Basis Sets in Resolution of the Identity MP2 Calculations. J. Chem. Phys. 2002, 116, 3175-3183. [CrossRef]

165. Zakrzewska, A.; Zaleśny, R.; Kolehmainen, E.; Ośmiałowski, B.; Jędrzejewska, B.; Ågren, H.; Pietrzak, M. Substituent Effects on the Photophysical Properties of Fluorescent 2-benzoylmethylenequinoline Difluoroboranes: A Combined Experimental and Quantum Chemical Study. Dyes Pigm. 2013, 99, 957-965. [CrossRef]

166. Ośmiałowski, B.; Zakrzewska, A.; Jędrzejewska, B.; Grabarz, A.; Zaleśny, R.; Bartkowiak, W.; Kolehmainen, E. Influence of Substituent and Benzoannulation on Photophysical Properties of 1-Benzoylmethyleneisoquinoline Difluoroborates. J. Org. Chem. 2015, 80, 2072-2080. [CrossRef] [PubMed]

167. Grabarz, A.M.; Laurent, A.D.; Jęrzejewska, B.; Zakrzewska, A.; Jacquemin, D.; Ośmiałowski, B. The Influence of the $\pi$ Conjugated Spacer on Photophysical Properties of Difluoroboranyls Derived from Amides Carrying a Donor Group. J. Org. Chem. 2016, 81, 2280-2292. [CrossRef]

168. Grabarz, A.M.; Jędrzejewska, B.; Zakrzewska, A.; Zaleśny, R.; Laurent, A.D.; Jacquemin, D.; Ośmiałowski, B. Photophysical Properties of Phenacylphenantridine Difluoroboranyls: Effect of Substituent and Double Benzannulation. J. Org. Chem. 2017, 82, 1529-1537. [CrossRef]

169. Grabarz, A.M.; Jędrzejewska, B.; Skotnicka, A.; Murugan, N.A.; Patalas, F.; Bartkowiak, W.; Jacquemin, D.; Ośmiałowski, B. The Impact of the Heteroatom in a Five-Membered Ring on the Photophysical Properties of Difluoroborates. Dyes Pigm. 2019, 170, 107481. [CrossRef]

170. Douhal, A.; Amat-Guerri, F.; Acuña, A.U. Photoinduced Intramolecular Proton Transfer and Charge Redistribution in Imidazopyridines. J. Phys. Chem. 1995, 99, 76-80. [CrossRef]

171. Skonieczny, K.; Ciuciu, A.I.; Nichols, E.M.; Hugues, V.; Blanchard-Desce, M.; Flamigni, L.; Gryko, D.T. Bright, Emission Tunable Fluorescent Dyes Based on Imidazole and $\pi$-expanded Imidazole. J. Mater. Chem. 2012, 22, 20649-20664. [CrossRef]

172. Stasyuk, A.J.; Banasiewicz, M.; Cyrański, M.K.; Gryko, D.T. Imidazo[1,2-a]pyridines Susceptible to Excited State Intramolecular Proton Transfer: One-Pot Synthesis via an Ortoleva-King Reaction. J. Org. Chem. 2012, 77, 5552-5558. [CrossRef]

173. Stasyuk, A.J.; Cywiński, P.J.; Gryko, D.T. Excited-State Intramolecular Proton Transfer in 2'-(2'-hydroxyphenyl)imidazo[1,2a]pyridines. J. Photochem. Photobiol. C 2016, 28, 116-137. [CrossRef]

174. Skonieczny, K.; Yoo, J.; Larsen, J.M.; Espinoza, E.M.; Barbasiewicz, M.; Vullev, V.I.; Lee, C.H.; Gryko, D.T. How To Reach Intense Luminescence for Compounds Capable of Excited-State Intramolecular Proton Transfer? Chem. Eur. J. 2016, 22, 7485-7496. [CrossRef]

175. Aginagalde, M.; Vara, Y.; Arrieta, A.; Zangi, R.; Cebolla, V.L.; Delgado-Camón, A.; Cossío, F.P. Tandem [8 + 2] Cycloaddition-[2 $+6+2$ ] Dehydrogenation Reactions Involving Imidazo[1,2-a]pyridines and Imidazo[1,2-a]pyrimidines. J. Org. Chem. 2010, 75, 2776-2784. [CrossRef] [PubMed]

176. Mutai, T.; Ohkawa, T.; Shono, H.; Araki, K. The Development of Aryl-Substituted 2-phenylimidazo[1,2-a]pyridines (PIP) with Various Colors of Excited-State Intramolecular Proton Transfer (ESIPT) Luminescence in the Solid State. J. Mater. Chem. C 2016, 4, 3599-3606. [CrossRef]

177. Tanaka, K.; Kurushima, T.; Iwata, S.; Shimada, S. Fluorescent Behavior of 2-(3,4,5,6-tetrafluoro-2-hydroxyphenyl)imidazo-[1,2a]pyridine in the Presence of Metal Perchlorate. J. Heterocyc. Chem. 2007, 44, 303-307. [CrossRef]

178. Balijapalli, U.; Iyer, S.K. CuO-CuAl${ }_{2} \mathrm{O}_{4}$ and D-glucose Catalyzed Synthesis of a Family of Excited State Intramolecular Proton Transfer Imidazo[1,2-a]pyridine Analogues and their Optical Properties. Dyes Pigm. 2015, 121, 88-98. [CrossRef] 
179. Silva-Junior, M.R.; Sauer, S.P.; Schreiber, M.; Thiel, W. Basis Set Effects on Coupled Cluster Benchmarks of Electronically Excited States: CC3, CCSDR(3) and CC2. Mol. Phys. 2010, 108, 453-465. [CrossRef]

180. Kozma, B.; Tajti, A.; Demoulin, B.; Izsák, R.; Nooijen, M.; Szalay, P.G. A New Benchmark Set for Excitation Energy of Charge Transfer States: Systematic Investigation of Coupled Cluster Type Methods. J. Chem. Theory Comput. 2020, 16, $4213-4225$. [CrossRef] [PubMed] 